\title{
Novel association between TGFA, TGFB1, IRF1, PTGS2 and IKBKB single-nucleotide polymorphisms and occurrence, severity and treatment response of major depressive disorder
} \author{
Szemraj $^{2}$, Tomasz Sliwinski ${ }^{\text {Corresp. } 1}$

Katarzyna Białek ${ }^{1}$, Piotr Czarny ${ }^{2}$, Cezary Watała ${ }^{3}$, Paulina Wigner ${ }^{1}$, Monika Talarowska ${ }^{4}$, Piotr Gałecki ${ }^{5}$, Janusz

Background: Activation of immune system might affect severity of depressive episodes as well as response to the antidepressant treatment. The purpose of this study was to investigate whether the occurrence of variant alleles of analyzed SNPs are involved in prevalence and progression of depression. Moreover, selected genes and SNPs have not been investigated in context of the disease severity and treatment. Therefore, six polymorphisms were selected: g.41354391A>G-TGFB1 (rs1800469), g.132484229C>A-IRF (rs2070729), g.186643058A>G-PTGS2 (rs5275), g.186640617C>T-PTGS2 (rs4648308), g.70677994G>A-TGFA (rs2166975) and g.42140549G>T-IKBKB (rs5029748).

Methods: A total of 360 (180 patients and 180 controls) DNA samples were genotyped using TaqMan probes.

Results: We observed that $A / G$ of the rs2166975 TGFA, A/C of rs2070729 IRF1 and G/T of rs5029748 $I K B K B$ were associated with an increased risk of depression development while theT/T of rs5029748 IKBKB, T/T of rs4648308 PTGS2 and G/G of rs2166975 TGFA reduced this risk. We also stratified the study group according to gender and found that genotype $A / G$ and allele $G$ of the rs2166975 TGFA, G/T of rs5029748 IKBKB as well as C allele of rs4648308 PTGS2, homozygote A/A and allele A of rs5275 PTGS2 were associated with increased risk of depression development in men while homozygote G/G of rs5275 PTGS2 decreased this risk. Moreover, C/T of rs4648308 PTGS2 and A/G of rs5275 PTGS2 was positively correlated with the risk of the disease occurrence in women. Furthermore, a gene-gene analysis revealed a link between studied polymorphisms and depression. In addition, A/A of rs1800469 TGFB1 was associated with earlier age of onset of the disease while G/G of this SNP increased severity of the depressive episode. Interestingly, A/C of rs2070729 IRF1 and T/T of rs5029748 IKBKB may modulate the effectiveness of selective serotonin reuptake inhibitors therapy. Concluding, studied SNPs may modulate the risk of occurrence, age of onset, severity of the disease and response to the antidepressant treatment. 
1 Novel association between TGFA, TGFB1, IRF1, PTGS2 and 2 IKBKB single-nucleotide polymorphisms and occurrence, 3 severity and treatment response of major depressive disorder

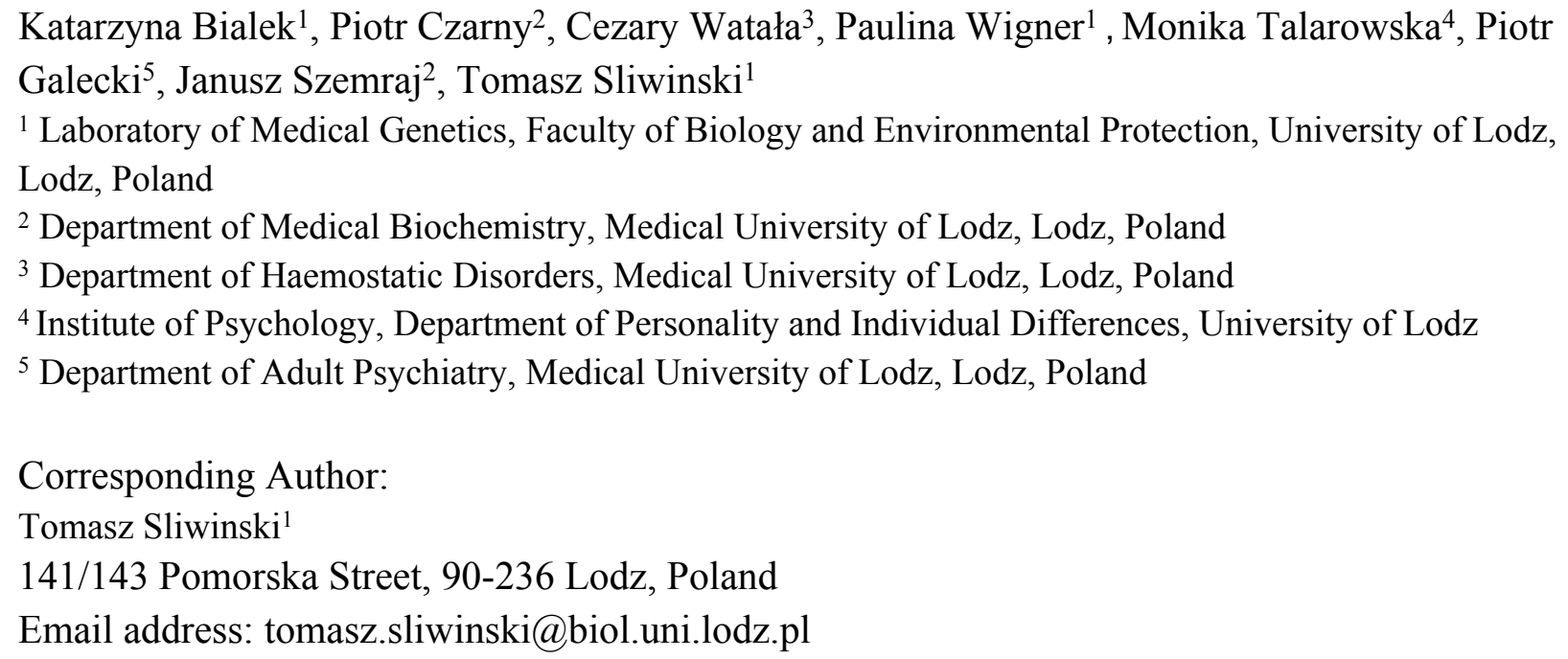

Background: Activation of immune system might affect severity of depressive episodes as well as response to the antidepressant treatment. The purpose of this study was to investigate whether the occurrence of variant alleles of analyzed SNPs are involved in prevalence and progression of depression. Moreover, selected genes and SNPs have not been investigated in context of the disease severity and treatment. Therefore, six polymorphisms were selected: g.41354391A $>\mathrm{G}-$ TGFB1 (rs1800469), g.132484229C $>\mathrm{A}-I R F$ (rs2070729), g.186643058A $>\mathrm{G}-P T G S 2$ (rs5275), g.186640617C $>$ T-PTGS2 (rs4648308), g.70677994G $>A-T G F A \quad$ (rs2166975) and g.42140549G $>$ T- IKBKB (rs5029748).

Methods: A total of 360 (180 patients and 180 controls) DNA samples were genotyped using TaqMan probes.

Results: We observed that $\mathrm{A} / \mathrm{G}$ of the rs2166975 TGFA, A/C of rs2070729 IRF1 and G/T of rs5029748 IKBKB were associated with an increased risk of depression development while theT/T of rs5029748 IKBKB, T/T of rs4648308 PTGS2 and G/G of rs2166975 TGFA reduced this risk. We also stratified the study group according to gender and found that genotype $A / G$ and allele $G$ of the rs2166975 TGFA, G/T of rs5029748 IKBKB as well as C allele of rs4648308 PTGS2, 
36

37

38

39

40

41

42

43

44

45

46

47

48

49

50

51

52

53

54

55

56

57

58

59

60

61

62

63

64

65

66

homozygote A/A and allele A of rs5275 PTGS2 were associated with increased risk of depression development in men while homozygote $\mathrm{G} / \mathrm{G}$ of rs5275 PTGS2 decreased this risk. Moreover, $\mathrm{C} / \mathrm{T}$ of rs4648308 PTGS2 and A/G of rs5275 PTGS2 was positively correlated with the risk of the disease occurrence in women. Furthermore, a gene-gene analysis revealed a link between studied polymorphisms and depression. In addition, A/A of rs1800469 TGFB1 was associated with earlier age of onset of the disease while G/G of this SNP increased severity of the depressive episode. Interestingly, $\mathrm{A} / \mathrm{C}$ of $\mathrm{rs} 2070729 I R F 1$ and $\mathrm{T} / \mathrm{T}$ of $\mathrm{rs} 5029748 I K B K B$ may modulate the effectiveness of selective serotonin reuptake inhibitors therapy. Concluding, studied SNPs may modulate the risk of occurrence, age of onset, severity of the disease and response to the antidepressant treatment.

\section{Introduction}

Depression (Major depressive disorder, MDD) is one of the most frequently diagnosed mental diseases. According to World Health Organization, about 350 million people suffer from this disorder all over the World (WHO 2019). Despite the importance of the problem, pathogenesis of depression is not fully understood. However, there is a growing body of evidence suggesting that immune system impairment and dysregulation is associated with the pathophysiology of MDD. Particularly the 'cytokine hypothesis' is widely accepted as one of the mechanisms for the development of depression (Capuron and Miller 2011). This theory postulates that MDD is a result of elevated expression of pro-inflammatory cytokines, which act as neuromodulators as well as main agents in mediation of the neuroendocrine, neurochemical and behavioral features of the disease (Schiepers et al. 2005). Some evidence confirmed link between inflammation and depression. Primarily, MDD patients exhibit increased levels of cytokines and other proinflammatory markers (Capuron and Miller 2011). Additionally, medical conditions connected with increased inflammatory response are associated with greater risk of MDD developing (Capuron and Miller 2011).

One of the cytokine class strongly associated with depression are interferons (IFN), cluster of signaling proteins involved in immune response. More than twenty different IFN proteins have been identified so far, and divided into classes. IFN proteins are able to activate immune cells, e.g. natural killer cells (NK cells) and macrophages (Pinto and Andrade 2016). For instance, IFN- $\alpha$ is implicated in modulation of mood, behavior and sleep-wake cycle, partially by its ability to 
67 activate the pro-inflammatory cytokine network including, interleukin 1 (IL-1), interleukin 6 (IL68 6) and tumor necrosis factor alpha (TNF- $\alpha$ ) (Zahiu and Mihai, 2014 ). IFN and IFN-inducible genes, involved in immunity and inflammation, are transcriptionally regulated by interferon regulatory factor 1 (IRF1) (Tamura et al. 2008). IRF1 was a first identified transcription factor in IFN system, and as a member of interferon regulatory factor family, plays important role in controlling expression of aforementioned genes (Kroger et al. 2002). Besides this, IRF1 promotes inflammatory cytokine release and regulates expression of interleukin 12 (IL-12) and interleukin 15 (IL-15), which are involved in MDD (Tamura et al. 2008).

Besides cytokine theory, various inflammatory pathways are thought to be activated in course of depression, including activation of the NF-kB (nuclear factor-kB), what leads to increased levels of pro-inflammatory cytokines (Bierhaus et al. 2003, Pace at al. 2006). NF-kB is a ubiquitous transcriptional factor that regulates expression of genes involved in pleiotropic functions, including pro-inflammatory cytokines and co-stimulatory molecules (Takeda and Akira 2007, Krauker 2008, Zhang et al, 2017). Inactive NF-kB molecules retain in the cytoplasm by interaction with $\mathrm{IkB}$ proteins, allowing to immediate activation in response to adequate impulse (Napetsching and $\mathrm{Wu} 2013$ ). Canonical signaling of NF-kB is activated by IkB kinase (IKK complex), consisting of three subunits, each encoded by separate gene, i.e. IKK-a (Inhibitor of nuclear factor kappa-B kinase subunit alpha) encoded by $C H U K$ gene, IKK-B (inhibitor of nuclear factor kappa-B kinase subunit beta) by $I K B K B$ gene and IKK-g (inhibitor of nuclear factor kappa-B kinase subunit gamma) by $I K B K G$. The activation of IKK is induced by phosphorylation of serine residues in catalytic subunits of kinase complex (Napetsching and Wu 2013, Karin 2000, Cardinez 2018). Therefore, defective expression of NF-kB as the pro-inflammatory transcription factor, caused by alterations in $I K B K B$ gene, may play a role in the development of depression (Napetsching and $\mathrm{Wu} 2013$ ).

Transforming growth factors (TGF) constitute of two classes of polypeptide growth factors, namely TGFA (transforming grow factor $\alpha$ ) and TGFB (transforming grow factor $\beta$ ). Important functions of these cytokines are embryonic development and regulation of specific reactions of immune system by their ability to induce T regulatory cells (Treg) (Kissin et al. 2002, Yamagiwa et al. 2001). TGFA is a ligand for epidermal growth factor receptor, which stimulates cell migration and proliferation. These gene and protein have been associated with many types of cancers and other diseases (Dijke et al. 2004). Another piece of evidence confirmed that TGFB, an anti- 
98 inflammatory cytokine, plays role in brain inflammation as well as in peripheral immune response.

99 Namely, TGFB is mainly involved in regulating inflammatory response by induction of 100 differentiation of CD4 ${ }^{+} \mathrm{T}$ cells (Nam et al. 2008, Passos et al. 2010). Other essential function of 101 the protein is cell to cell signaling, and thus controlling of cell growth and differentiation (Dijke 102 et al. 2004). In addition, TGFB is able to exert neuroprotective effects in many neurodegenerative 103 disorders (Vivien and Ali 2006 ). Information about its role in depression are contradictory. On 104 the one hand, in animal model of depression, the cytokine level is increased, and causes imbalance 105 between Treg and Th17 cells (Hong et al. 2013). On the other hand, some studies reported that 106 levels of TGFB in depressed patients are lower than in healthy control group (Musil et al. 2011, 107 Sutcigil et al. 2007). Moreover, TGFB alone is sufficient to stimulate production of pro108 inflammatory cytokines e.g. IL-1 and TNF- $\alpha$ (Kunzmann et al. 2003). The protein is also able to 109 induce expression of prostaglandin-endoperoxide synthase 2 (PTGS2; cyclooxygenase-2 - COX110 2) encoded by PTGS2 gene, which is involved in pathogenesis of MDD. PTGS2 besides 111 contribution to processes related to inflammation, also participates in the production of free 112 radicals, which is partly utilized by PTGS2 itself (Aktan 2004, Hansson et al. 2006). Moreover, 113 COX-2 catalyzes conversion of arachidonic acid (AA) to prostaglandins (PGs), which further 114 intensify inflammation and neurodegenerative processes in central nervous system (CNS) 115 (Minghetti 2004). In response to growth factors, cytokines and other inflammatory molecules, 116 PTGS2 is immediately expressed and is responsible for the production of prostanoid in both acute 117 and chronic inflammatory conditions (Breyer et al. 2001, Shi et al. 2010). Additionally, in animal 118 model of depression increased expression of PTGS2 was observed in brain regions (Cassano et al. 119 2006).

The evidence suggests, that MDD may be associated with impairment of immune system, caused by defective activity of aforementioned genes. Moreover, genetic factors may play an essential role in development of depression, since genome-wide association studies (GWAS) 123 found several regions significantly associated with MDD (Shyn et al. 2011, Wray et al. 2018). 124 Therefore, the present study examines the prospective relationship between the occurrence, age of 125 onset, severity or antidepressant treatment efficacy of MDD and appearance of single nucleotide 126 polymorphism (SNP) located in inflammatory-related genes, i.e. g.132484229C $>$ A of IRF1 127 (rs2070729, located on 5q31.1), g.186643058A $>\mathrm{G}$ of PTGS2 (rs5275, located on 1q31.1), 128 g.186640617C $>$ T of PTGS2 (rs4648308, located on 1q31.1), g.70677994G $>$ A of TGFA 
129 (rs2166975, located on 2p13.3), g.41354391A $>$ G of $T G F B 1$ (rs 1800469, located on 19q13.2), and 130 g.42140549G $>$ T of $I K B K B$ (rs5029748, located on 8p11.21). Selected SNPs are located within 131 immune genes participating in inflammatory-related signaling pathways. Therefore, they could 132 affect gene expression and protein function, and thus contribute to immune disruptions leading to 133 increased risk of MDD.

134 Materials \& Methods

135 Subjects

136 The study included a total of 360 participants randomly selected. A group of 180 patients with 137 depression hospitalized at the Department of Adult Psychiatry of the Medical University of Lodz, 138 and 180 volunteers without health problems, selected randomly (Table 1). Participants who took 139 part in the experiment were native, not-related Poles. Patients were included based on the criteria 140 set out in ICD-10 (F32.0-7.32.2, F33.0-F33.8). Medical and psychiatric records were obtained in 141 accordance with ICD-10 criteria, using the Standardized Composite International Diagnostic 142 Interview (CIDI). The depression' severity was evaluated using the 21-item Hamilton Depression 143 Rating Scale (HDRS-21). The exclusion criteria included: axis I and II disorders other than MDD, 144 chronic somatic diseases, autoimmune disorders (psoriasis, rheumatoid arthritis, chronic 145 obstructive pulmonary disease, cancer, chronic kidney disease, systemic lupus erythematosus, type 1461 diabetes, hepatitis $\mathrm{B}$ and $\mathrm{C}$ virus, and HIV infection), neuroinflammatory and neurodegenerative 147 disorders (including multiple sclerosis, Alzheimer's disease, Parkinson's disease) and central 148 nervous system damage. Furthermore, subjects with familial incidence of mental diseases, other 149 than MDD did not participate in the experiment. Psychiatric examination was conducted by the 150 same psychiatrist, before the subjects were included in the experiment and after 8 weeks of 151 pharmacotherapy with SSRI (selective serotonin reuptake inhibitor). Control group included 152 selected randomly, volunteers with negative history of mental disorders. Participation in the 153 experiment was voluntary. Controls and patients who did not agree to participate in the study were excluded. The purpose of the study was clearly presented, participants were assured that their personal information would be kept confidential. All of the subjects agreed to participate in the 156 experiment according to the protocol approved by the Bioethics Committee of the Medical University of Lodz (No. RNN/70/14/KE). 


\section{SNP selection}

159 Selection of the studied polymorphisms was performed using the public domain of the database 160 for single nucleotide polymorphisms of the National Center for Biotechnology (NCBI dbSNP, 161 www.ncbi.nlm.nih.gov/snp/) (Bethesda, Montgomery County, MD, USA). The criteria used for 162 the SNPs' selection were that the minor allele frequency is greater than 0.05 in the European 163 population, and that they are located in the coding or regulatory region of the genes and may have 164 functional meaning for transcription and protein function. Detailed information about selected 165 polymorphisms are presented in Table 2.

\section{DNA isolation}

167 Genomic DNA was isolated from venous blood in accordance with the manufacturer instructions. 168 Blood samples were collected from control group and patients with MDD. Blood Mini Kit (A\&A 169 Biotechnology, Gdynia, Poland) was used to extract nucleic acid. The purity of and concentration 170 of the DNA was measured spectrophotometrically by calculating the ratio between absorbance at $171260 \mathrm{~nm}$ and $280 \mathrm{~nm}$, using Picodrop ${ }^{\mathrm{TM}}$ (Picodrop Limited, Astranet Systems Ltd., UK). Samples 172 were stored at $-20^{\circ} \mathrm{C}$ until use.

\section{Genotyping}

174 The investigated SNPs were genotyped using a TaqMan SNP Genotyping Assay (Thermo Fisher 175 Scientific, Waltham, Massachusetts, USA), and a 2X Master Mix Takyon for Probe Assay - No 176 ROX (Eurogentec, Liège, Belgium). Reactions were conducted in accordance with the 177 manufacturer's instruction. Real-time PCR were performed with a Bio-Rad CFX96 Real-Time 178 PCR Detection System, and analysed in CFX Manager Software (Bio-Rad Laboratories Inc., 179 Hercules, California, USA).

\section{Statistical analysis}

181 The collected data were analyzed in Statistica 12 (Statsoft, USA), SigmaPlot 14.0 (Systat Software 182 Inc., USA), Resampling Stats Add-in for Excel v.4 (Arlington, USA) and StudSize3.02 (CreoStat 183 HB, Sweden). The descriptive statistics are shown as medians with interquartile ranges. Normality 184 of the studied group was verified with the Shapiro-Wilk test, homogeneity of variance was 185 checked with Brown-Forsythe test. Accordingly, either the unpaired Student's $t$ test or Mann186 Whitney $U$ test was used. To calculate the associations between studied polymorphisms and the 187 occurrence of a disease an unconditional multiple logistic regression model was used. The results 188 are shown as odds ratio (OR) with 95\% confidence interval $(95 \% \mathrm{CI})$. The OR values were 
189 adjusted for the potential confounders, including age and sex. We also stratified results into male

190

191

192

193

194

195

196

197

198

199

200

201

202

203

204

205

206

207

208

209

210

211

212

213

214

215

216

217

and female group and evaluated correlation between case/control for each polymorphism. In addition, in order to strengthen that the revealed differences were not detected by a pure chance the significant outcomes were further validated with the use of two approaches: the bootstrapboosted multiple logistic regression (resampling with replacement, 10000 iterations) and the crossvalidated logistic regression (corresponding to the $d$-jackknife technique), with the patient group acting as the modelled class. This was intended to overcome any possible bias related to relatively low sample sizes. The goodness of fit of logistic regression models showing a significant degree of discrimination between controls and patients was estimated with Hosmer-Lemeshow test.

Efficiency of the treatment was calculated using the formula as described before (Czarny et al. 2019):

$$
T E=\frac{\left(H A M \text { ? 目 } D_{0}-H A M \text { 年 } D_{E}\right) \times 100 \%}{H A M \text { 国 } D_{0}}
$$

TE- treatment efficiency; HAM-D $\mathrm{D}_{0}$ - score before therapy; HAM-D $\mathrm{E}_{\mathrm{E}}-$ score after therapy

\section{Results}

Single nucleotide polymorphisms of genes encoding IRF1, IKBKB, TGFA, TGFB and PTGS2 as a risk of MDD

The distribution of genotypes and alleles in both depressed and control groups was in agreement with Hardy-Weinberg equilibrium. Results are presented in Table 3. The results demonstrated that the $\mathrm{A} / \mathrm{G}$ genotype of the g.70677994G $>\mathrm{A}$ (rs2166975) polymorphism of the TGFA gene is associated with an increased risk of depression development, while $\mathrm{G} / \mathrm{G}$ genotype decreased this risk. Furthermore, in case of IRF1, carriers of A/C genotype of the g.132484229C >A (rs2070729) have a greater chance of developing the disease. Moreover, the $\mathrm{T} / \mathrm{T}$ homozygote of g.186640617C $>$ T (rs4648308) of PTGS2 gene is negatively correlated with risk of MDD development. Similarly, In the case of g.42140549G>T (rs5029748) polymorphism of $I K B K B$, we found that T/T homozygote decreased risk of MDD occurrence, while the heterozygote of the same gene variant decreased this risk. 
218 Single-nucleotide polymorphisms of genes encoding IRF1, IKBKB, TGFA, TGFB and 219 PTGS2 and MDD occurrence in male and female population

220 Since women show two-times higher risk of MDD occurrence compared to men, we decided to 221 investigated the association between prevalence of the disease in stratified male/female population 222 and all studied SNPs. Results are presented in Table 4. The results demonstrated that in the case 223 of g.70677994G $>\mathrm{A}$ (rs2166975) polymorphism of the $T G F A$, the $\mathrm{A} / \mathrm{G}$ genotype increased the 224 risk of MDD in men, but not in women. Moreover, allele A of this SNP was associated with 225 decreased chance of the disease, while allele $\mathrm{G}$ was strongly correlated with higher risk of MDD. 226 Furthermore, in male population allele $\mathrm{G}$ and G/G homozygote of the g.186643058A $>$ G (rs5275) 227 of PTGS2 decreased risk of depression while, allele $\mathrm{A}$ and $\mathrm{A} / \mathrm{A}$ homozygote of the same 228 polymorphism was associated with increased risk of the occurrence of the disease. Additionally, 229 it was found that A/G genotype of this SNP was correlated with higher risk of MDD in the female 230 group. Another SNP of PTGS2 gene, g.186640617C $>$ T (rs4648308) was associated with MDD 231 risk in both studied groups. Precisely, C/T genotype was positively correlated with the risk of the 232 occurrence of MDD in women. Similarly, allele $\mathrm{C}$ of the mentioned polymorphism increased 233 prevalence of the disease among men, while allele $\mathrm{T}$ decreased this risk. We also found that 234 genotypes of g.42140549G $>\mathrm{T}$ (rs5029748) polymorphism of $I K B K B$ gene were related with 235 appearance of MDD in male population. Particularly, G/T genotype was connected with increased 236 risk of depression, while T/T genotype of the same SNP decreased this risk.

237

\section{Gene-gene interactions of IRF1, IKBKB, TGFA, TGFB and PTGS2 and the risk of MDD}

239

In this research, we also studied whether the combined genotypes of investigated polymorphism are associated with appearance of MDD. Results are presented in Table 5. In reference to effect of combined genotypes, it was found that G/G-T/T genotypes of g.70677994G>A (rs2166975) TGFA and g.186640617C $>\mathrm{T}$ (rs4648308) - PTGS2 was associated with decreased risk of 243 depression occurrence, while A/G-C/T genotypes increased this risk. The A/G-A/C genotypes of 244 g.70677994G $>$ A (rs2166975) - TGFA and g.132484229C $>$ A (rs2070729) - IRF1 as well as A/GA/G genotypes of g.70677994G $>$ A (rs2166975) TGFA and g.41354391A $>\mathrm{G}(\mathrm{rs} 1800469)-T G F B$ also increased the risk of the disease. Furthermore, higher risk of MDD occurrence was associated with the G/T-A/G genotypes of g.42140549G $>$ T (rs5029748) - IKBKB and g.186643058A $>\mathrm{G}$ 
249 genotypes of g.70677994G >A (rs2166975) - TGFA and g.186643058A >G (rs5275) - PTGS2, we 250 found that link between $\mathrm{A} / \mathrm{G}-\mathrm{G} / \mathrm{G}$ of this genes was associated with higher risk of appearance of 251 the MDD, while G/G-G/G as well as A/A-G/G genotypes decreased this chance. Similarly, A/G252 G/T combined genotypes of g.70677994G $>$ A (rs2166975) - TGFA and g.42140549G $>$ T 253 (rs5029748) - IKBKB increased risk of MDD but G/G-T/T genotypes of the same SNP were 254 associated with lower risk of disease incidence. Moreover, carriers of $\mathrm{A} / \mathrm{C}-\mathrm{A} / \mathrm{G}$ combined 255 genotypes of g.132484229C $>\mathrm{A}$ (rs2070729) - IRF1 and g.186643058A $>\mathrm{G}$ (rs5275) - PTGS, 256 A/C-G/T of g.132484229C $>$ A (rs2070729) - IRF1 and g.42140549G $>$ T (rs5029748) - IKBKB as 257 well as G/T-C/T genotypes of g.42140549G $>$ T (rs5029748) - IKBKB and g.186640617C $>$ T 258 (rs4648308) - PTGS2 had a greater risk of MDD appearance.

259

260

Single-nucleotide polymorphisms of genes encoding IRF1, IKBKB, TGFA, TGFB, PTGS2 261 and the age of the first episode of MDD and the severity classification on the Hamilton 262 Depression Rating Scale

263

To estimate whether the investigated polymorphisms may had an impact on the age of the first 264 episode of MDD, patients were stratified in accordance to genotype and their age of onset was 265 compared (Figure 1). A significant difference was found between A/A and A/G genotypes as well 266 as $\mathrm{A} / \mathrm{A}$ and $\mathrm{G} / \mathrm{G}$ genotypes of g.41354391A $>\mathrm{G}$ (rs1800469) - TGFB1. Carriers of A/A genotype 267 had their first episode significantly earlier compared to other genotypes.

268 In the case of the impact of genotypes of the investigated SNPs on the episode severity measured 269 using the Hamilton Depression Rating Scale (HDRS) (Figure 2), significant differences was found 270 between carriers of $\mathrm{A} / \mathrm{A}$ and $\mathrm{G} / \mathrm{G}$ genotypes of g.41354391A $>\mathrm{G}$ (rs1800469) - TGFB1.

271

272

Single-nucleotide polymorphisms of genes encoding IRF1, IKBKB, TGFA, TGFB, PTGS2, 273 and effectiveness of depression treatment

274

We also evaluated impact of the studied polymorphisms on the effectiveness of antidepressant 275 treatment with selective serotonin reuptake inhibitor (SSRI) (Figure 3). Regarding the effect of investigated SNPs on treatment efficiency, differences was found between A/A and A/C genotypes 277 of g.132484229C $>$ A (rs2070729) - IRF1 as well as G/G and T/T genotypes of g.42140549G $>$ T 278 (rs5029748) - IKBKB.

279

\section{Discussion}


280 There is strong amount of evidence that inflammation is undeniably associated with major 281 depressive disorder. Moreover, it was confirmed that some inflammatory genes and presence of 282 their genetics variants play important role in MDD development. Additionally, several 283 loci/chromosomal regions connected with MDD were mapped by genome-wide linkage analysis, 284 i.e. 1q32.1, 2p25.1, 3p21.1, 3p26.1, 3q26.1, 6p22.3, 8q22.2, 8q22.3, 8q12.1, 8q23.3, 11p14.2285 p14.3, 13q31.1-q31.3, 15q25.2 and 19q12 (McGuffin et al. 2005, Shyn et al. 2011, Sullivan et al. 286 2013). Selected candidate genes in current study are located in proximity to the above mentioned 287 regions of chromosomes. In this research, we genotyped six polymorphic variants of $T G F A$, 288 TGFB1, IRF1 and PTGS2 genes; and to our knowledge, none of this SNPs have been studied in 289 the context of severity and treatment response in depression before. However, these SNPs were 290 included in GWAS but only one of them, i.e. rs2070729, had $p$ value below 0.05 .

291 The first of investigated polymorphisms in this study was g.70677994G >A (rs2166975) - TGFA.

292 The SNP is localized on 2p13.3 and it is responsible for synonymous change Val159Val. This 293 terminal amino acid is present in the precursor protein and is necessary for glycosylation during 294 protein maturation as well as protein localization to the cell surface (Briley et al. 1997). In our 295 study, we were the first to show a link between rs2166975 polymorphism of TGFA and depression. 296 The results confirmed that A/G genotype of rs2166975 is more frequently distributed in patients 297 suffering from depression. Interestingly, the same genotype increased the risk of MDD only in 298 man population. In the case of the gene-gene interactions between polymorphism of TGFA and 299 other SNPs, analysis confirmed that A/G-A/C combined genotypes of rs2166975 - TGFA and 300 rs207072 - IRF1 are associated with higher chance to develop MDD. In addition, A/G-G/G 301 genotypes of rs2166975 - TGFA and rs5275 - PTGS2 is associated with higher risk of MDD, 302 while G/G-G/G homozygotes decreased this chance. It was indicated that rs2166975 in TGFA 303 gene, showed association with the risk of cleft palate (Morkuniene et al. 2007). Furthermore, 304 another study confirmed, using transmission disequilibrium test, that minor allele of rs 2166975 305 was over-transmitted to cleft-palate cases (Carter et al. 2010). Although there are no studies 306 investigating role of rs2166975 polymorphism in depression or any other psychiatric disorders, 307 our results suggest important role of investigated polymorphism in pathophysiology and course of 308 depression.

309 The second studied SNP, g.41354391A $>$ G (rs1800469) of TGFB1, is located on 19q13.2 in the 310 proximal negative regulatory region of the gene. The human TGFB1 protein is considered to be 
311 one of the immunosuppressive cytokines, which plays crucial role in CNS development (Sousa et 312 al. 2004). It is responsible for such functions as astrocyte differentiation, synaptogenesis and 313 neuronal migration (Sampaio e Spohr et al. 2002, Sousa et al. 2004, Feng et al. 2008, Siegenthaler 314 et al. 2004). Our results show that rs1800469 polymorphism is associated with both severity of 315 depressive episodes and age of the onset of the disease. Precisely, carriers of G/G genotype are 316 characterized by more severe episodes than A/A genotype carriers, which may correlate with 317 increased concentrations of TGFB1. Moreover, a significant difference in the age of the first 318 episode of MDD was found between $\mathrm{A} / \mathrm{A}$ and $\mathrm{A} / \mathrm{G}$ genotypes, as well as $\mathrm{A} / \mathrm{A}$ and $\mathrm{G} / \mathrm{G}$ genotypes 319 of rs1800469 - TGFB1. In accordance to our findings, TGFB levels were found to be increased 320 in people suffering from MDD (Davami et al. 2016, Kim et al. 2007, Kim et al. 2008) as well as 321 in Chronic HBV-Infected Patients (CHB) with mild depression symptoms (Bahramabadi et al. 322 2017). It has been reported that rs 1800469, is not associated with neither Alzheimer's disease risk 323 (Chang et al. 2013) nor Schizophrenia (Kapelski et al. 2015). However rs 1800469 of TGFB1 is 324 associated with altered plasma levels of TGFB1, which may modulate a susceptibility to MDD 325 (Shah et al. 2006, Wang et al. 2008). Data suggest that, allele G is associated with lower expression 326 of TGFB1 (Shah et al. 2006). On the other hand, another study confirmed that genotypes A/G and $327 \mathrm{G} / \mathrm{G}$ was correlated with increased plasma TGFB1 concentrations, indicating that $\mathrm{G}$ allele is 328 associated with higher production of the protein (Wang et al. 2008). It was found that other SNPs 329 of TGFB1 could be associated with MDD. In the case of rs1800470 (codon 10), genotype T/T is 330 significantly more frequently distributed in depressed patients (Mihailova et al. 2016). Moreover, 331 another study revealed that $\mathrm{C} / \mathrm{C}$ genotype of the same SNP is positively correlated with higher risk 332 of depression development and more severe episodes of the disease (Caraci et al., 2012). Although 333 TGFB1 is considered to play important role in psychoneuroimmunology, there is only few research 334 about its association with mental disorders, and interestingly there is no other studies investigated 335 role of mentioned rs1800469 in MDD.

336 In our study we also investigated whether SNPs in PTGS2 gene are involved in MDD development. 337 As mentioned in Introduction, PTGS2 participates in inflammatory processes partly related with 338 neurodegeneration in CNS (Minghetti et al 2004). There is evidence demonstrating that rs20417 339 polymorphism of PTGS2 may play a role in MDD. Precisely, presence of G allele is strongly 340 associated with increased risk of depression development (Galecki et al. 2010). However, we have not included this polymorphism in our study. Instead, we explored g.186640617C > T (rs4648308) 
342 polymorphism located on 1q31.1. There are evidence of its involvement in depression. Precisely, 343 allele $\mathrm{T}$ and $\mathrm{C} / \mathrm{T}$ genotype (in positive strand allele $\mathrm{A}$ and $\mathrm{G} / \mathrm{A}$ genotype ) of mentioned SNP are 344 associated with significantly increased risk of IFN- $\alpha$-induced depression (Su et al. 2010). Part of 345 our result are consistent with this findings, namely, we found that $\mathrm{C} / \mathrm{T}$ heterozygote increased risk 346 of MDD in woman, as well as the $\mathrm{C}$ allele increased this chance in man group. On the contrary, 347 we also reported that T/T genotype carriers of this SNP are less likely to develop depression in 348 general population. Similarly, in man group allele T was also negatively correlated with depression 349 prevalence.

350 Second polymorphism of PTGS2 gene, g.186643058A $>$ G (rs5275) located on 1q31.1, is a 351 functional SNP, which modulates expression of PTGS2. We were first to found that allele G is 352 connected with higher chance of MDD occurrence. Additionally, it is confirmed that this SNP is 353 associated with severe pain in lung cancer patients. Namely, A/A and A/G (in forward strand T/T

354

355 356

357

358

359

360

361

362

363

364

365 366

367 368 369 370

371 372 and T/C) carriers experience more severe pain than G/G carriers (Reyes-Gibby et al. 2009, ReyesGibby et al. 2013). However, Mendlewicz et al. (2012) found no association between PTGS2 rs5275 polymorphism and treatment response and remission of MDD. Still, there are no other studies investigated aforementioned SNPs in PTGS2 gene in context of MDD.

Another SNP candidate in our research was g.42140549G $>$ T (rs5029748) of $I K B K B$ gene. It is located on 8 p11.21, in intronic region of the gene, thus do not cause amino acid substitution. We were first to analyze the mentioned polymorphism as a risk factor for MDD. Our main finding relates to the connection between this SNP and effectiveness of depression treatment. Namely, we demonstrated differences in SSRI response between carriers of G/G and T/T genotypes. Moreover, presence of G/T genotype of rs5029748 is associated with increased risk of MDD development either in general or man population, while the T/T homozygote of the same gene variant reduces this risk in the same studied groups. In addition, carrier of combined G/T-A/G genotypes of rs5029748 - IKBKB and rs5275 - PTGS2 are more likely to develop MDD, while T/T-G/G genotype showed protective effect. Moreover A/G-G/T genotype of rs5029748IKBKB and rs2166975 - TGFA, increased risk of depression but G/T-T/T are associated with lower risk of disease. The trend of increasing risk of depression prevalence is also present in the case of linked genotypes of rs5029748 - IKBKB and rs4648308 - PTGS2. Some studies revealed association between aforementioned SNP and risk of colorectal or colon cancer (Seufert et al. 2013, Curtin et al. 2013). Precisely, minor allele T of rs5029748, was associated with decreased risk of colon 
373 cancer (Curtin et al. 2010). Although our result showed that single-nucleotide polymorphism of

$374 I K B K B$ may play significant role in MDD, they have not been investigated in pathogenesis of the 375 disease before.

376 The g.132484229C >A (rs2070729) - IRF1 polymorphism was the last studied SNP in this paper.

377 It is located on 5q31.1 in intronic gene region. The SNP is associated with susceptibility to hepatitis

378 C virus (HCV) infection (Fortunato et al. 2008). What is more, allele $\mathrm{C}$ of this SNP is linked to

379 higher vulnerability HIV-1 acquisition (Lingappa et al. 2011). To our best knowledge, we were 380 first to analyze role of rs2070729 in MDD. Regarding the effect of investigated SNP on treatment 381 efficiency, data in our study showed significant differences in antidepressant response between $382 \mathrm{~A} / \mathrm{A}$ and $\mathrm{A} / \mathrm{C}$ genotypes of rs2070729 - IRF1, A/A carriers were more likely to better treatment 383 response. Exact explanation of this mechanism has not been elucidated yet in previous research. 384 However, since A allele is a minor one in European population, we speculate that it might be 385 associated with decreased expression of IRF1 and thus reduction of inflammatory cytokine release.

386 Therefore, together with anti-inflammatory properties of antidepressants it could enhance the their 387 effect. We also found that carriers of A/C genotype of rs2070729 - IRFI were linked with $\mathrm{A} / \mathrm{G}$ 388 of rs5275 - PTGS or G/T of rs5029748 - IKBKB had a greater risk of MDD appearance. These 389 results suggest that SNP in $I R F 1$ gene may have impact in depression development.

390 Our preliminary study has several potential limitations. Firstly, the sample size was relatively 391 small. Nevertheless, two resampling approaches were performed so as to minimise the risk of 392 obtaining false positive results. Another limitation was the homogenic ethnicity of studied group. 393 This could reduce the potential to extrapolate the results to other ethnic groups. Furthermore, it 394 must be emphasised that there is limited data on the impact of these SNPs on the level of mRNA 395 and protein expression/activity. Consequently, presented results should be considered preliminary 396 and interpreted with caution.

397

398 Conclusions

399 The single-nucleotide polymorphisms located in IRF1, IKBKB, TGFA, TGFB1, PTGS2 genes 400 modulate the risk of occurrence, age of onset, severity of the disease and response to the 401 antidepressant treatment. Our result suggest that inflammatory pathways, in which studied genes 402 are involved may be at least partially implicated in etiology of MDD. Moreover, discovery about 403 impact of IRFI and IKBKB SNPs on treatment response could contribute to the discovery of 
404 effective, personalized pharmacotherapy. However, future studies should elucidate the implication 405 of the studied polymorphisms in biological functions, e.g. mRNA and protein expression, protein 406 activity. On the whole, our results might cast a new light on the pathogenesis of major depressive 407 disorders.

408

409

410

411

412

413

414

415

416

417

418

419

420

421

422

423

424

425

426

427

428

429

430

431

432

433

434

435

\section{References}

1. Aktan, F., iNOS-mediated nitric oxide production and its regulation. Life Sciences. 2004; 75, 639-653.

2. Bahramabadi R, Fathollahi MS, Hashemi SM, Arababadi AS, Arababadi MS, Yousefi-Daredor H, Bidaki R, Khaleghinia M, Bakhshi MH, Yousefpoor Y, Torbaghan, YE, Arababadi MK. Serum Levels of IL-6, IL-8, TNF- $\alpha$, and TGF- $\beta$ in Chronic HBV-Infected Patients: Effect of Depression and Anxiety. Lab Med. 2017; 22;49(1):41-46

3. Bierhaus A, Wolf J, Andrassy M, Rohleder N, Humpert PM, Petrov D, Ferstl R, von Eynatten M, Wendt T, Rudofsky G, Joswig M, Morcos M, Schwaninger M, McEwen B, Kirschbaum C, Nawroth PP. A mechanism converting psychosocial stress into mononuclear cell activation. Proc Natl Acad Sci U S A. 2008;18:100(4):1920-5

4. Breyer, R. M., Bagdassarian, C. K., Myers, S. A. \& Breyer, M. D. Prostanoid receptors: subtypes and signaling. Annu. Rev. Pharmacol. Toxicol. 2001; 41, 661-690

5. Briley GP, Hissong MA, Chiu ML, Lee DC, The carboxyl-terminal valine residues of proTGF alpha are required for its efficient maturation and intracellular routing. Mol Biol Cell. 1997; 8:1619-1631

6. Capuron L, Miller AH. Immune system to brain signaling: neuropsychopharmacological implications. Pharmacol Ther. 2011;130(2):226-384

7. Caraci F, Bosco P, Signorelli M, Spada RS, Cosentino FI, Toscano G, Bonforte C, Muratore S, Prestianni G, Panerai S, Giambirtone MC, Gulotta E, Romano C, Salluzzo MG, Nicoletti F, Copani A, Drago F, Aguglia E, Ferri R. The CC genotype of transforming growth factor- $\beta 1$ increases the risk of late-onset Alzheimer's disease and is associated with AD-related depression. Eur Neuropsychopharmacol. 2012;22(4):281-9.

8. Cardinez C, Miraghazadeh B, Tanita K, da Silva E, Hoshino A, Okada S, Chand R, Asano T, Tsumura M, Yoshida K, Ohnishi H, Kato Z, Yamazaki M, Okuno Y, Miyano S, Kojima S, Ogawa S, Andrews TD, Field MA, Burgio G, Morio T, Vinuesa CG, Kanegane H, Cook 
MC. Gain-of-function IKBKB mutation causes human combined immune deficiency. J

437

438

439

440

441

442

443

444

445

446

447

448

449

450

451

452

453

454

455

456

457

458

459

460

461

462

463

464

465

Exp Med. 2018;5,215(11):2715-2724

9. Carter TC, Molloy AM, Pangilinan F, Troendle JF, Kirke PN, Conley MR, Orr DJ, Earley M, McKiernan E, Lynn EC, Doyle A, Scott JM, Brody LC, Mills JL. Testing reported associations of genetic risk factors for oral clefts in a large Irish study population. Birth Defects Res A Clin Mol Teratol. 2010;88(2):84-93.

10. Cassano P, Hidalgo A, Burgos V, Adris S, Argibay P. Hippocampal upregulation of the cyclooxygenase-2 gene following neonatal clomipramine treatment (amodel of depression). The Pharmacogenomics Journal 2006;6, 381-387.

11. ChangWW., Zhang L, Jin YL, Yao, YS. Meta-analysis of the transforming growth factorbetal polymorphisms and susceptibility to Alzheimer's disease. J. Neural Transm. $2013 ; 120(2), 353-360$.

12. Curtin K, Wolff RK, Herrick JS, Abo R, Slattery ML. Exploring multilocus associations of inflammation genes and colorectal cancer risk using hapConstructor. BMC Med Genet. $2013 ; 3 ; 11: 170$

13. Czarny P, Wigner P, Strycharz J, Swiderska E, Synowiec E, Szatkowska M, Sliwinska A, Talarowska M, Szemraj J, Su KP, Maes M, Sliwinski T, Galecki P. Mitochondrial DNA copy number, damage, repair and degradation in depressive disorder. World $\mathrm{J}$ Biol Psychiatry. 2019;13:1-11

14. Davami MH, Baharlou R, Ahmadi Vasmehjani A, Ghanizadeh A, Keshtkar M, Dezhkam I, Atashzar MR. Elevated IL-17 and TGF- $\beta$ Serum Levels: A Positive Correlation between T-helper 17 Cell-Related Pro-Inflammatory Responses with Major Depressive Disorder. Basic Clin Neurosci. 2016;7(2):137-42.

15. Feng Z, Ko CP. Schwann cells promote synaptogenesis at the neuromuscular junction via transforming growth factor-beta1. The Journal of neuroscience : the official journal of the Society for Neuroscience. 2008;28(39):9599-609.

16. Fortunato G, Calcagno G, Bresciamorra V, Salvatore E, Filla A, Capone S, Liguori R, Borelli S, Gentile I, Borrelli F, Borgia G, Sacchetti L. Multiple sclerosis and hepatitis C virus infection are associated with single nucleotide polymorphisms in interferon pathway genes. J Interferon Cytokine Res. 2008;28(3):141-52

Peer) reviewing PDF | (2019:10:42178:1:1:NEW 22 Jan 2020) 
466

467

468

469

470

471

472

473

474

475

476

477

478

479

480

481

482

483

484

485

486

487

488

489

490

491

492

493

494

495

17. Gałecki P, Florkowski A, Bieńkiewicz M, Szemraj J. Functional polymorphism of cyclooxygenase-2 gene (G-765C) in depressive patients. Neuropsychobiology. 2010;62(2):116-20

18. Hansson M, Olsson I, Nauseef WM. Biosynthesis, processing, and sorting of human myeloperoxidase. Archives of Biochemistry and Biophysics. 2006;445, 214-224.

19. Hong M, Zheng J, Ding ZY, Chen JH, Yu L, Niu Y, Hua YQ, Wang LL. Imbalance between Th17 and Treg cells may play an important role in the development of chronic unpredictable mild stress-induced depression in mice. Neuroimmunomodulation. 2013;20(1):39-50

20. Kapelski P, Skibinska M, Maciukiewicz M, Wilkosc M, Frydecka D, Groszewska A, Narozna B, Dmitrzak-Weglarz M, Czerski P, Pawlak J, Rajewska-Rager A, LeszczynskaRodziewicz A, Slopien A, Zaremba D, Twarowska-Hauser J. Association study of functional polymorphisms in interleukins and interleukin receptors genes: IL1A, IL1B, IL1RN, IL6, IL6R, IL10, IL10RA and TGFB1 in schizophrenia in Polish population. Schizophr Res. 2015;169(1-3):1-9

21. Karin M and Ben-Neriah Y., Phosphorylation meets ubiquitination: the control of NF- $\kappa \mathrm{B}$ activity, Annual Review of Immunology, 2000;18:621-663

22. Kim YK, Na KS, Shin KH., Jung HY, Choi SH, Kim JB. Cytokine imbalance in the pathophysiology of major depressive disorder. Progress in Neuropsychopharmacological and Biological Psychiatry, 2007; 31(5), 1044-1053.

23. Kim YK, Lee SW, Kim SH, Shim SH, Han SW, Choi SH, Lee BH, Differences in cytokines between non-suicidal patients and suicidal patients in major depression. Progress in Neuropsychopharmacological and Biological Psychiatry. 2008; 32(2), 356361.

24. Kissin EY, Lemaire R, Korn JH, Lafyatis R. Transforming growth factor beta induces fibroblast fibrillin-1 matrix formation. Arthritis Rheum. 2002;46:3000-3009.

25. Krakauer $\mathrm{T}$. Nuclear factor- $\kappa \mathrm{B}$ : fine-tuning a central integrator of diverse biologic stimuli. International Reviews of Immunology. 2008; 27(5):286-292

26. Kröger A, Köster M, Schroeder K, Hauser H, Mueller PP. Activities of IRF-1. J Interferon Cytokine Res. 2002;22(1):5-14 
496

497

498

499

500

501

502

503

504

505

506

507

508

509

510

511

512

513

514

515

516

517

518

519

520

521

522

523

524

525

526

27. Kunzmann, S, Mantel PY., Wohlfahrt JG, Akdis M, Blaser K, Schmidt-Weber CB. Histamine enhances TGF-beta1-mediated suppression of Th2 responses. FASEB J. 2003;17, 1089-1095.

28. Lingappa JR, Petrovski S, Kahle E, Fellay J, Shianna K, McElrath MJ, Thomas KK, Baeten JM, Celum C, Wald A, de Bruyn G, Mullins JI, Nakku-Joloba E, Farquhar C, Essex M, Donnell D, Kiarie J, Haynes B, Goldstein D; Partners in Prevention HSV/HIV Transmission Study Team. Genomewide association study for determinants of HIV-1 acquisition and viral set point in HIV-1 serodiscordant couples with quantified virus exposure. PLoS One. 2011;6(12):e28632

29. McGuffin P, Knight J, Breen G, Brewster S, Boyd PR, Craddock N, Gill M, Korszun A, Maier W, Middleton L, Mors O, Owen MJ, Perry J, Preisig M, Reich T, Rice J, Rietschel M, Jones L, Sham P, Farmer AE. Whole genome linkage scan of recurrent depressive disorder from the depression network study. Hum Mol Genet. 2005;15;14(22):3337-45

30. Mendlewicz J, Crisafulli C, Calati R, Kocabas NA, Massat I, Linotte S, Kasper S, Fink M, Sidoti A, Scantamburlo G, Ansseau M, Antonijevic I, Forray C, Snyder L, Bollen J, Montgomery S, Zohar J, Souery D, Serretti A. Influence of COX-2 and OXTR polymorphisms on treatment outcome in treatment resistant depression. Neurosci Lett. 2012;10;516(1):85-8

31. Mihailova S, Ivanova-Genova E, Lukanov T, Stoyanova V, Milanova V, Naumova E., A study of TNF- $\alpha$, TGF- $\beta$, IL-10, IL- 6 , and IFN- $\gamma$ gene polymorphisms in patients with depression. J Neuroimmunol. 2016;293:123-128.

32. Minghetti L. Cyclooxygenase-2 (COX-2) in inflammatory and degenerative brain diseases. J. Neuropathol. Exp. Neurol. 2004;63, 901-910

33. Morkūniené A, Steponaviciūt D, Utkus A, Kucinskas V. Few associations of candidate genes with nonsyndromic orofacial clefts in the population of Lithuania. J Appl Genet. 2007;48(1):89-91

34. Musil R, Schwarz MJ, Riedel M, Dehning S, Cerovecki A, Spellmann I, Arolt V, Müller N. Elevated macrophage migration inhibitory factor and decreased transforming growth factor-beta levels in major depression--no influence of celecoxib treatment. J Affect Disord. 2011;134(1-3):217-25 
527

528

529

530

531

532

533

534

535

536

537

538

539

540

541

542

543

544

545

546

547

548

549

550

551

552

553

554

555

35. Nam JS, Terabe M, Kang MJ, Chae H, Voong N, Yang YA, Laurence A, Michalowska A, Mamura M, Lonning S, Berzofsky JA, Wakefield LM. Transforming growth factor beta subverts the immune system into directly promoting tumor growth through interleukin-17. Cancer Res. 2008; 15;68(10):3915-23

36. Napetschnig J, Wu H. Molecular Basis of NF-kB Signaling. Annual Review Biophys 2013;443-68.

37. Pace TW, Mletzko TC, Alagbe O, Musselman DL, Nemeroff CB, Miller AH, Heim CM. Increased stress-induced inflammatory responses in male patients with major depression and increased early life stress. Am J Psychiatry. 2006;163(9):1630-3

38. Passos ST, Silver JS, O'Hara AC, Sehy D, Stumhofer JS, Hunter CA. IL-6 promotes NK cell production of IL-17 during toxoplasmosis. J Immunol. 2010. 15;184(4):1776-83

39. Pinto EF, Andrade C. Interferon-Related Depression: A Primer on Mechanisms, Treatment, and Prevention of a Common Clinical Problem. Curr Neuropharmacol. 2016;14(7):743-8

40. Reyes-Gibby CC, Spitz MR, Yennurajalingam S, Swartz M, Gu J, Wu X, Bruera E, Shete S. Role of inflammation gene polymorphisms on pain severity in lung cancer patients. Cancer Epidemiol Biomarkers Prev. 2009;18(10):2636-42

41. Reyes-Gibby CC, Swartz MD, Yu X, Wu X, Yennurajalingam S, Anderson KO, Spitz MR, Shete S. Symptom clusters of pain, depressed mood, and fatigue in lung cancer assessing the role of cytokine genes. Support Care Cancer. 2013;21(11):3117-25

42. Sampaio e Spohr TC, Martinez R, da Silva EF, Neto VM, Gomes FC. Neuro-glia interaction effects on GFAP gene: a novel role for transforming growth factor-beta1. The European journal of neuroscience.2002;16(11):2059-69.

43. Schiepers OJ, Wichers MC, Maes M. Cytokines and major depression. Prog Neuropsychopharmacol Biol Psychiatry. 2005;29(2):201-17

44. Seufert BL, Poole EM, Whitton J, Xiao L, Makar KW, Campbell PT, Kulmacz RJ, Baron

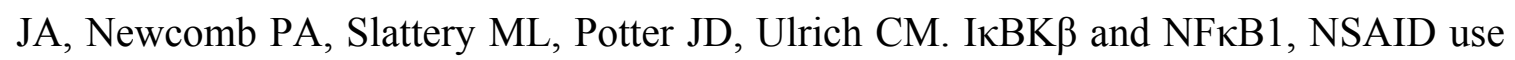
and risk of colorectal cancer in the Colon Cancer Family Registry. Carcinogenesis. 2013;34(1):79-85

Peer) reviewing PDF | (2019:10:42178:1:1:NEW 22 Jan 2020) 
556

557

558

559

560

561

562

563

564

565

566

567

568

569

570

571

572

573

574

575

576

577

578

579

580

581

582

583

584

585

586

45. Shah R, Rahaman B, Hurley CK, Posch PE. Allelic diversity in the TGFB1 regulatory region:characterization of novel functional single nucleotide polymorphisms. Hum. Genet. 2006;119(1-2): 61-74.

46. Shi J, Johansson J, Woodling NS, Wang Q, Montine TJ, Andreasson K. The prostaglandin E2 E-prostanoid 4 receptor exerts anti-inflammatory effects in brain innate immunity. J. Immunol. 2010;184, 7207-7218

47. Shyn SI, Shi J, Kraft JB, Potash JB, Knowles JA, Weissman MM, Garriock HA, Yokoyama JS, McGrath PJ, Peters EJ, Scheftner WA, Coryell W, Lawson WB, Jancic D., Gejman PV, Sanders AR, Holmans P, Slager SL, Levinson DF, Hamilton SP. Novel loci for major depression identified by genome-wide association study of Sequenced Treatment Alternatives to Relieve Depression and meta-analysis of three studies. Mol Psychiatry. 2011;16(2):202-15

48. Siegenthaler JA, Miller MW. Transforming growth factor beta1 modulates cell migration in rat cortex: effects of ethanol. Cereb Cortex. 2004;14(7):791-802.

49. Sousa Vde O, Romao L, Neto VM, Gomes FC. Glial fibrillary acidic protein gene promoter is differently modulated by transforming growth factorbeta 1 in astrocytes from distinct brain regions. The European journal of neuroscience. 2004;19(7):1721-30.

50. Su KP, Huang SY, Peng CY, Lai HC, Huang CL, Chen YC, Aitchison KJ, Pariante CM. Phospholipase A2 and cyclooxygenase 2 genes influence the risk of interferon-alphainduced depression by regulating polyunsaturated fatty acids levels. Biol Psychiatry. 2010;15;67(6):550-7

51. Sullivan PF, Daly MJ, Ripke S, Lewis CM, Lin D-Y, Wray NR et al. A mega-analysis of genome-wide association studies for major depressive disorder. Molecular Psychiatry. 2013;18(4):497-511

52. Sutcigil L, Oktenli C, Musabak U, Bozkurt A, Cansever A, Uzun O, Sanisoglu SY, Yesilova Z, Ozmenler N, Ozsahin A, Sengul A. Pro- and anti-inflammatory cytokine balance in major depression: effect of sertraline therapy. Clin Dev Immunol. 2007;2007:76396.

53. Takeda K, Akira S. Toll-like receptors. Curr Protoc Immunol 2007;14(14):14.12

54. Tamura T, Yanai H, Savitsky D, Taniguchi T. The IRF family transcription factors in immunity and oncogenesis. Annu Rev Immunol. 2008;26:535-84

Peer) reviewing PDF | (2019:10:42178:1:1:NEW 22 Jan 2020) 
587

588

589

590

591

592

593

594

595

596

597

598

599

600

601

602

603

604

605

606

607
55. ten Dijke P, Hill CS. New insights into TGF-beta-Smad signalling. Trends Biochem Sci. 2004;29(5):265-73

56. Wang H, Zhao YP, Gao CF, Ji Q, Gressner AM, Yang ZX, Weiskirchen R, Transforming growth factor beta 1 gene variants increase transcription and are associated with liver cirrhosis in Chinese. Cytokine 2008; 43(1): 20-25.

57. WHO 2018: http://www.who.int/news-room/fact-sheets/detail/depression (August, 2019)

58. Wray NR, Ripke S, Mattheisen M, Trzaskowski M, Byrne EM, Abdellaoui A, Adams MJ, Agerbo E, Air TM, et.al.; Major Depressive Disorder Working Group of the Psychiatric Genomics Consortium. Genome-wide association analyses identify 44 risk variants and refine the genetic architecture of major depression. Nat Genet. 2018;50(5):668-681

59. Vivien D, Ali C. Transforming growth factor-beta signalling in braindisorders, Cytokine Growth Factor Rev. 2006;17 (1-2) 121-128,

60. Yamagiwa S, Gray JD, Hashimoto S, Horwitz DA. A role for TGF beta in the generation and expansion of $\mathrm{CD} 4+\mathrm{CD} 25+$ regulatory $\mathrm{T}$ cells from human peripheral blood. $\mathrm{J}$. Immunol. 2001; 166, 7282-7289.

61. Zahiu C, Mihai R. Neuropsychiatric side-effects of interferonalpha treatment: Pathophysiology and therapeutic options. MAEDICA - a Journal of Clinical Medicine. 2014;9(2), 121-126.

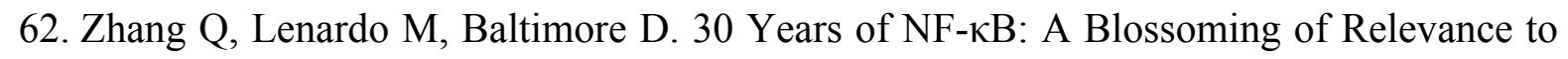
Human Pathobiology. Cell. 2017;168:37-57. 
Figure 1

Impact of single-nucleotide polymorphisms localized in inflammatory genes on the age of the first episode of MDD.

(A) TGFB1 g.41354391A > G (rs1800469) (B) TGFA g.70677994G>A (rs2166975) (C) IRF1 g.132484229C>A (rs2070729) (D) PTGS2 g.186643058A>G (rs5275) (E) PTGS2 g.186640617C>T (rs4648308) (F) IKBKB g.42140549G>T (rs5029748). Results are presented as scatter dot plots. The horizontal lines denote the median, while the whiskers show the inter-quartile range.

A

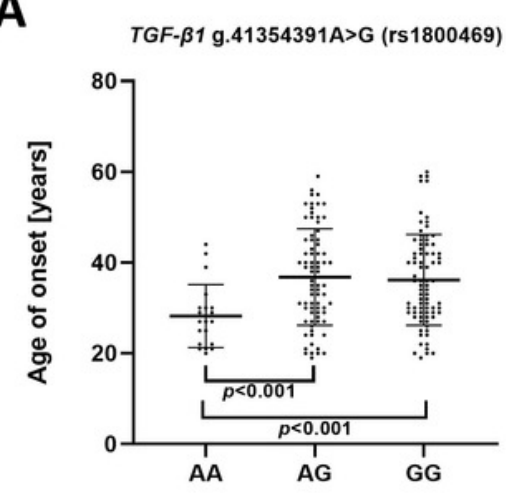

D

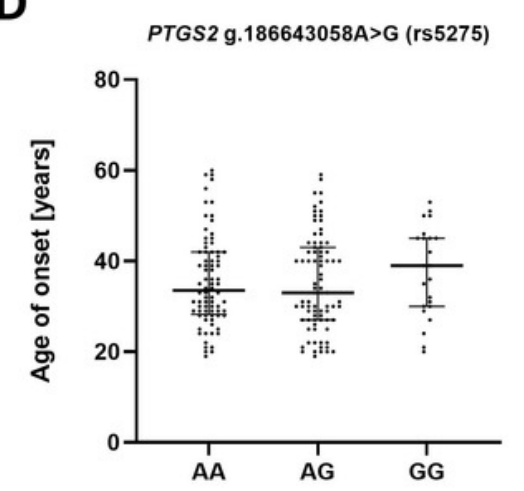

B

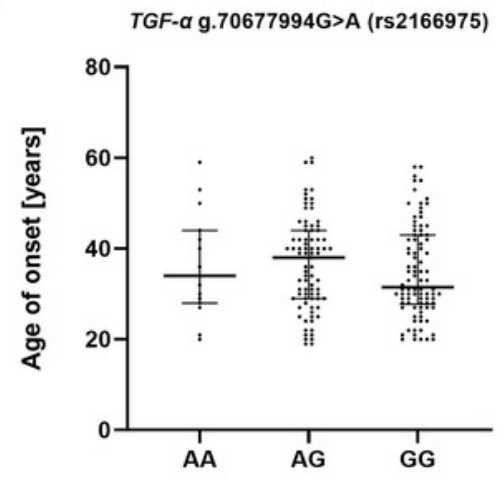

E

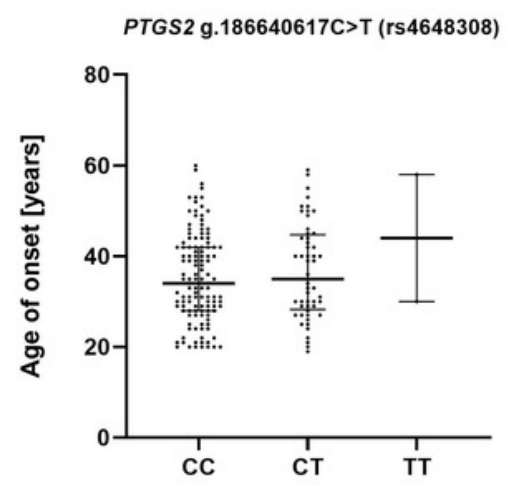

C

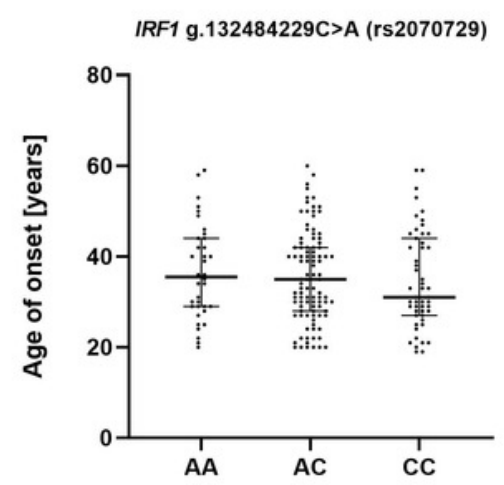

F

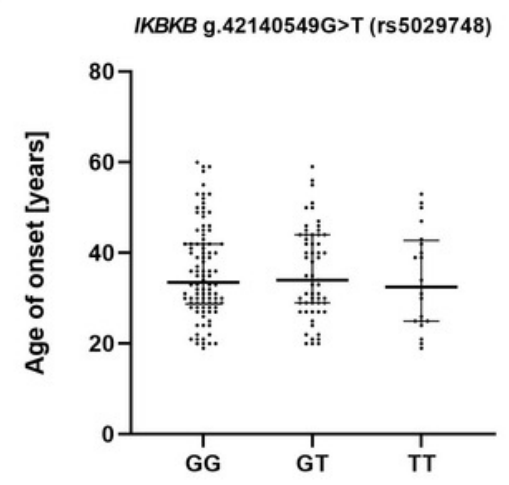




\section{Figure 2}

Distribution of the severity of episode (before therapy) and single nucleotide polymorphisms localized in inflammatory genes.

Severity of current episode according to 21-item Hamilton Depression Rating Scale (HAM-D)

(A) TGFB1 g.41354391A>G (rs1800469) (B) TGFA g.70677994G>A (rs2166975) (C) IRF1 g.132484229C >A (rs2070729) (D) PTGS2 g.186643058A>G (rs5275) (E) PTGS2 g.186640617C>T (rs4648308) (F) IKBKB g.42140549G > T (rs5029748). Results are presented as scatter dot plots. The horizontal lines denote the median, while the whiskers show the inter-quartile range.

A

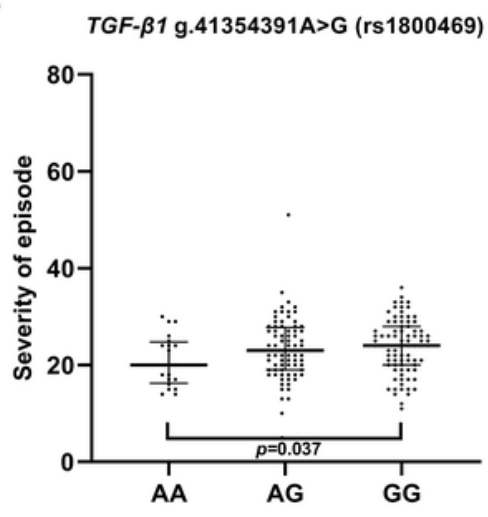

D

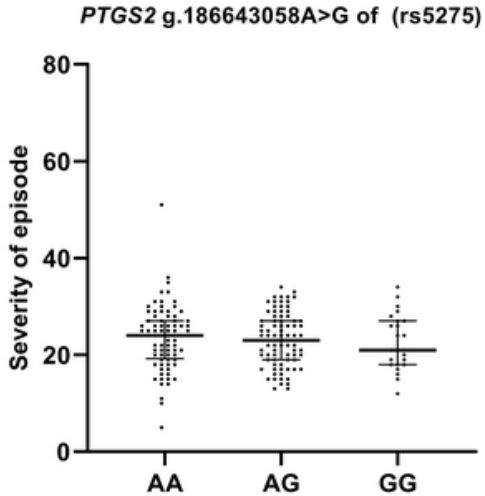

B

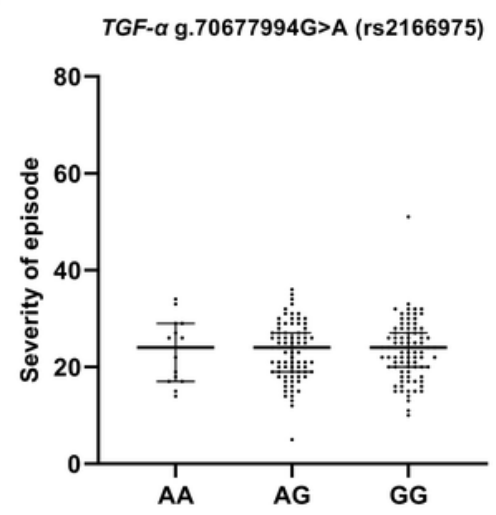

E

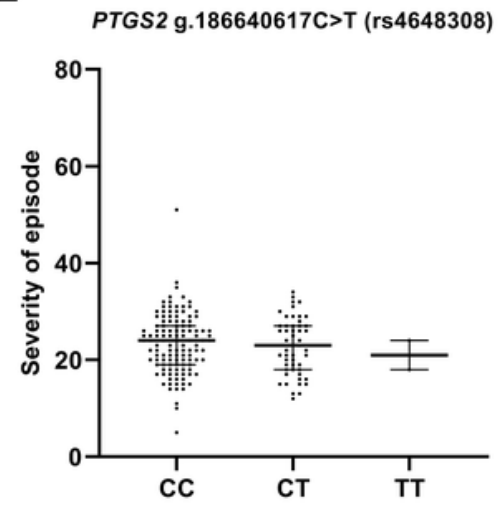

C

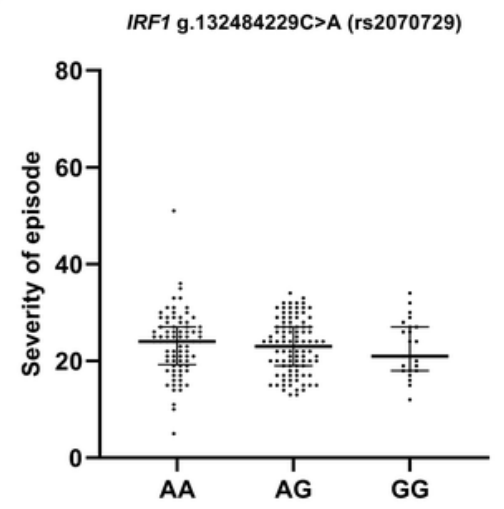

F

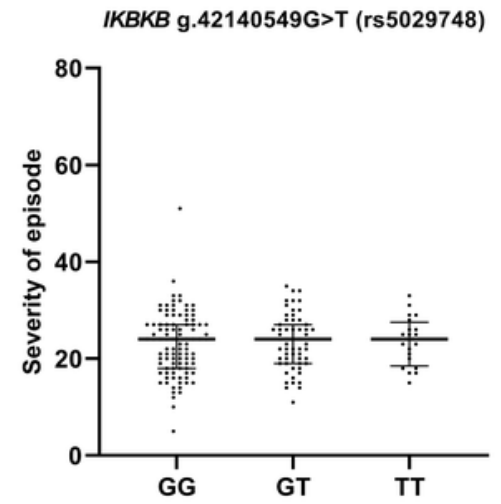


Figure 3

Impact of single-nucleotide polymorphisms localized in inflammatory genes on the effectiveness of the treatment.

Treatment effectiveness expressed as percentage of HAM-D decline after therapy.

A) TGFB1 g.41354391A>G (rs1800469) (B) TGFA g.70677994G >A (rs2166975) (C) IRF1 g.132484229C >A (rs2070729) (D) PTGS2 g.186643058A > G (rs5275) (E) PTGS2 g.186640617C >T (rs4648308) (F) IKBKB g.42140549G $>T$ (rs5029748). Results are presented as scatter dot plots. The horizontal lines denote the median, while the whiskers show the inter-quartile range.

A

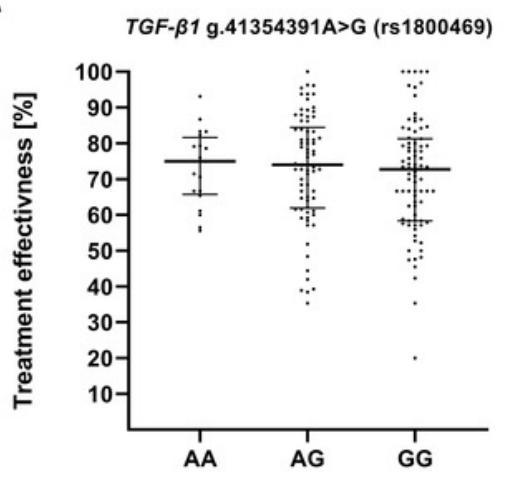

D

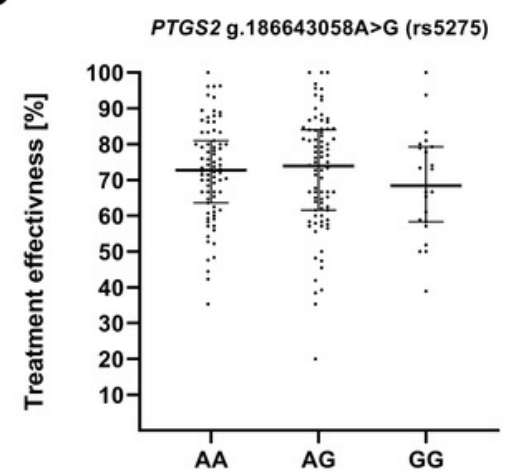

B

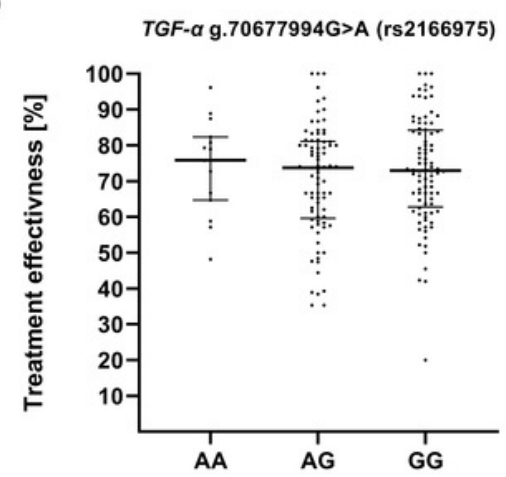

E

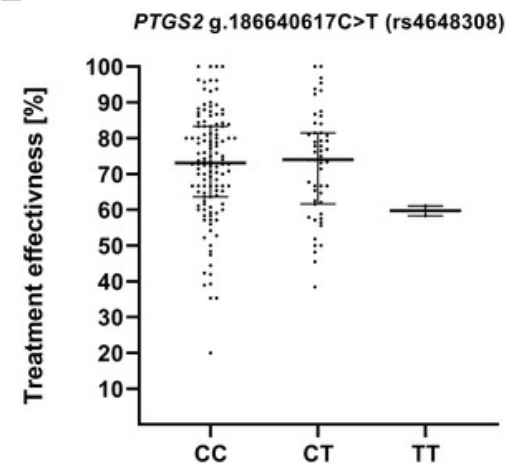

C

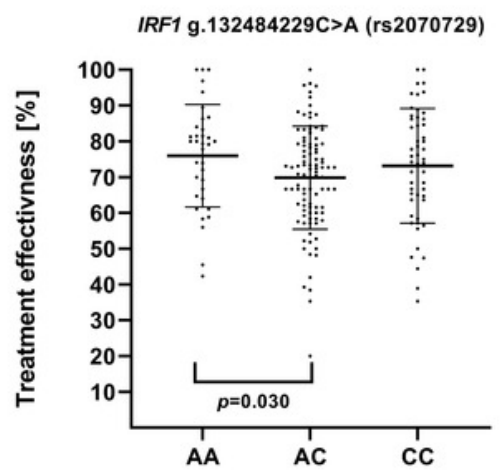

F

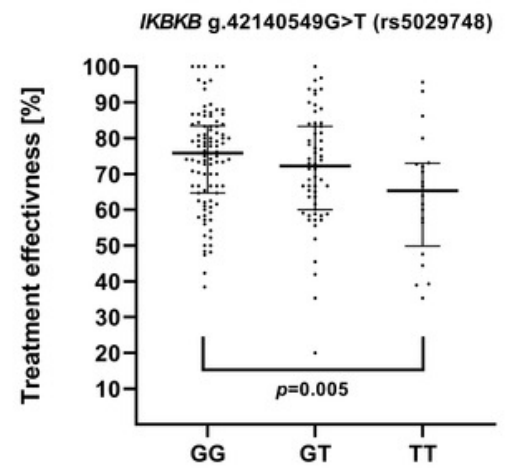




\section{Table 1 (on next page)}

Characteristic of studied population.

M means male; F means Female Mdn - median; Q1 - first quartile; Q3 - third quartile HRDS1

- points in Hamilton Depression Rating Scale measured before antidepressant treatment 


\begin{tabular}{|c|c|c|}
\hline Group & Control $(n=180)$ & Patients $(n=180)$ \\
\hline $\operatorname{Sex}(M / F)$ & $93 / 87$ & $91 / 89$ \\
\hline $\begin{array}{l}\text { Age } \\
\left(\operatorname{Mdn}\left[\mathrm{Q}_{1} ; \mathrm{Q}_{3}\right]\right)\end{array}$ & $57[50 ; 65]$ & $51[44 ; 56]$ \\
\hline $\begin{array}{l}\text { Age of onset } \\
\left(\mathrm{Mdn}\left[\mathrm{Q}_{1} ; \mathrm{Q}_{3}\right]\right)\end{array}$ & - & $34[28 ; 43]$ \\
\hline $\begin{array}{l}\operatorname{HRDS} 1 \\
\left(\operatorname{Mdn}\left[\mathrm{Q}_{1} ; \mathrm{Q}_{3}\right]\right)\end{array}$ & - & $24[19 ; 27]$ \\
\hline \multicolumn{3}{|l|}{ Treatment efficacy } \\
\hline $\begin{array}{l}\text { Responsive } \\
\text { (reduction from baseline of } \\
\geq 50 \% \text { in the total score) }\end{array}$ & & $93 \%$ \\
\hline $\begin{array}{l}\text { Remission } \\
\text { (total HRDS1 score } \leq 7 \text { ) }\end{array}$ & & $66 \%$ \\
\hline
\end{tabular}


Table 2 (on next page)

Characteristic of studied polymorphisms. 
1

\begin{tabular}{|c|c|c|c|c|}
\hline Gene & rs number & Polymorphis & Localization & $\begin{array}{l}\text { Minor allele } \\
\text { freqency }\end{array}$ \\
\hline$T G F A$ & rs2166975 & g. $70677994 \mathrm{G}>\mathrm{A}$ & Exon 5 & $\mathrm{~A}=0.256$ \\
\hline$T G F B$ & rs1800469 & g. $41354391 \mathrm{~A}>\mathrm{G}$ & $5^{\prime}$ of $T G F B$ gene & $\mathrm{A}=0.312$ \\
\hline$I R F 1$ & rs2070729 & g. $132484229 \mathrm{C}>\mathrm{A}$ & Intron 9 & $A=0.465$ \\
\hline$I K B K B$ & rs5029748 & g. $42140549 \mathrm{G}>\mathrm{T}$ & Intron 2 & $\mathrm{~T}=0.259$ \\
\hline \multirow{2}{*}{ PTGS2 } & rs5275 & g. $186643058 \mathrm{~A}>\mathrm{G}$ & 3' UTR of PTGS2 gene & $\mathrm{G}=0.310$ \\
\hline & rs4648308 & g. $186640617 \mathrm{C}>\mathrm{T}$ & 3' of PTGS2 gene & $\mathrm{T}=0.142$ \\
\hline
\end{tabular}




\section{Table 3 (on next page)}

Distribution of genotypes and alleles of rs1800469 (TGFB1), rs2070729 (IRF1), rs5275 (PTGS2), rs4648308 (PTGS2), rs2166975 (TGFA), rs5029748 (IKBKB) and the risk of depression occurrence

* 'adjusted OR' means OR adjusted for sex and age; for significant comparisons the superscript b means the bootstrap-boosted OR (resampling with replacement, 10000 iterations); all OR values without bootstrap analysis were calculated using cross-validation algorithm. Statistical power $(1-\beta)$ (calculated at $\alpha=0.05$ ) for significant comparisons given in superscripts. $p<0.05$ along with corresponding ORs are in bold 


\begin{tabular}{|c|c|c|c|c|c|c|c|c|}
\hline \multirow{2}{*}{$\begin{array}{l}\text { Genotype } \\
\text { /Allele }\end{array}$} & \multicolumn{2}{|l|}{ Control } & \multicolumn{2}{|c|}{ Depression } & \multirow{2}{*}{ Crude OR (95\% CI) } & \multirow{2}{*}{$p$} & \multirow{2}{*}{$\begin{array}{l}\text { Adjusted OR (95\% } \\
\text { CI)* }\end{array}$} & \multirow{2}{*}{$p$} \\
\hline & Number & Frequency & Number & Frequency & & & & \\
\hline \multicolumn{9}{|c|}{ g.41354391A $>\mathrm{G}$ of $T G F B 1$ (rs1800469) } \\
\hline $\mathrm{A} / \mathrm{A}$ & 23 & 0.128 & 20 & 0.117 & $0.853(0.451-1.616)$ & 0.626 & $0.739(0.367-1.49)$ & 0.398 \\
\hline $\mathrm{A} / \mathrm{G}$ & 71 & 0.394 & 76 & 0.428 & $1.231(0.623-2.432)$ & 0.550 & $1.197(0.762-1.879)$ & 0.435 \\
\hline G/G & 86 & 0.478 & 84 & 0.483 & $1.123(0.575-2.196)$ & 0.734 & $0.949(0.609-1.479)$ & 0.818 \\
\hline \multicolumn{9}{|c|}{$\chi 2=0.403 ; p=0.818$} \\
\hline A & 117 & 0.325 & 116 & 0.322 & $0.987(0.723-1.349)$ & 0.937 & $0.961(0.687-1.344)$ & 0.815 \\
\hline G & 243 & 0.675 & 244 & 0.678 & $1.013(0.741-1.384)$ & 0.937 & $1.041(0.744-1.456)$ & 0.815 \\
\hline \multicolumn{9}{|c|}{ g.70677994G $>$ A of $T G F A($ rs2166975) } \\
\hline $\mathrm{A} / \mathrm{A}$ & 27 & 0.142 & 15 & 0.081 & $0.530(0.272-1.031)$ & 0.062 & $0.576(0.280-1.184)$ & 0.133 \\
\hline $\mathbf{A} / \mathbf{G}$ & 59 & 0.311 & 83 & 0.446 & $\begin{array}{l}b 1.814(1.197-2.749) \\
1.789 \\
(1.173-2.728)^{0.692} \\
\end{array}$ & $\begin{array}{l}0.005 \\
0.007\end{array}$ & $\begin{array}{l}b_{2.115}(1.341-3.336) \\
2.091 \\
(1.323-3.304)^{0.893}\end{array}$ & $\begin{array}{l}0.001 \\
0.002\end{array}$ \\
\hline G/G & 104 & 0.547 & 88 & 0.473 & $0.743(0.495-1.114)$ & 0.150 & $\begin{array}{l}b 0.609(0.392-0.946) \\
0.615 \\
(0.395-0.957)^{0.691}\end{array}$ & $\begin{array}{l}0.027 \\
0.031\end{array}$ \\
\hline \multicolumn{9}{|c|}{$\chi 2=8.627 ; p=0.013$} \\
\hline A & 113 & 0.297 & 113 & 0.304 & $1.031(0.755-1.408)$ & 0.848 & $1.173(0.839-1.640)$ & 0.351 \\
\hline G & 267 & 0.703 & 259 & 0.696 & $0.970(0.710-1.325)$ & 0.848 & $0.853(0.610-1.192)$ & 0.351 \\
\hline \multicolumn{9}{|c|}{ g.132484229C $>$ A of $I R F 1$ (rs2070729) } \\
\hline $\mathrm{A} / \mathrm{A}$ & 37 & 0.209 & 36 & 0.193 & $0.902(0.540-1.507)$ & 0.694 & $0.883(0.507-1.539)$ & 0.661 \\
\hline $\mathbf{A} / \mathbf{C}$ & 76 & 0.429 & 99 & 0.529 & $\begin{array}{l}b_{1} .409(1.002-2.216) \\
1.495 \\
(0.989-2.261)^{0.457}\end{array}$ & $\begin{array}{l}0.048 \\
0.057\end{array}$ & $\begin{array}{l}b 1.504(0.963-2.348) \\
1.496 \\
(0.957-2.337)\end{array}$ & $\begin{array}{l}\mathbf{0 . 0 7 7} \\
\mathbf{0 . 0 7 3}\end{array}$ \\
\hline
\end{tabular}




\begin{tabular}{|c|c|c|c|c|c|c|c|c|}
\hline $\mathrm{C} / \mathrm{C}$ & 64 & 0.362 & 52 & 0.278 & $0.680(0.437-1.059)$ & 0.088 & $0.692(0.429-1.115)$ & 0.130 \\
\hline \multicolumn{9}{|c|}{$\chi 2=4.006 ; p=0.135$} \\
\hline A & 150 & 0.424 & 171 & 0.457 & $1.146(0.855-1.536)$ & 0.363 & $1.225(0.893-1.681)$ & 0.208 \\
\hline $\mathrm{C}$ & 204 & 0.576 & 203 & 0.543 & $0.873(0.651-1.170)$ & 0.363 & $0.816(0.595-1.120)$ & 0.208 \\
\hline \multicolumn{9}{|c|}{ g.42140549G $>\mathrm{T}$ of $I K B K B(\mathrm{rs} 5029748)$} \\
\hline G/G & 108 & 0.587 & 100 & 0.559 & $0.891(0.588-1.350)$ & 0.586 & $0.928(0.594-1.450)$ & 0.743 \\
\hline G/T & 40 & 0.217 & 59 & 0.330 & $\begin{array}{l}b 1.787(1.125-2.839) \\
1.770 \\
(1.108-2.829)^{0.551}\end{array}$ & $\begin{array}{l}\text { 0.014 } \\
0.017\end{array}$ & $\begin{array}{l}b_{1.813} \quad(1.072-3.066) \\
1.776 \\
(1.080-2.921)^{0.556}\end{array}$ & $\begin{array}{l}0.026 \\
0.024\end{array}$ \\
\hline $\mathbf{T} / \mathbf{T}$ & 36 & 0.196 & 20 & 0.112 & $\begin{array}{l}{ }^{b} 0.507(0.272-0.945) \\
0.517 \\
(0.286-0.934)^{0.647}\end{array}$ & $\begin{array}{l}\text { 0.032 } \\
0.029\end{array}$ & $\begin{array}{l}{ }^{b} 0.450(0.229-0.885) \\
0.461 \\
(0.243-0.877)^{0.759}\end{array}$ & $\begin{array}{l}0.021 \\
0.018\end{array}$ \\
\hline \multicolumn{9}{|c|}{$\chi 2=1.509 ; p=0.470$} \\
\hline G & 256 & 0.696 & 259 & 0.723 & $1.145(0.830-1.578)$ & 0.409 & $1.210(0.857-1.707)$ & 0.279 \\
\hline $\mathrm{T}$ & 112 & 0.304 & 99 & 0.277 & $0.874(0.634-1.204)$ & 0.409 & $0.827(0.586-1.167)$ & 0.279 \\
\hline \multicolumn{9}{|c|}{ g. $186643058 \mathrm{~A}>\mathrm{G}$ of $P T G S 2$ (rs5275) } \\
\hline $\mathrm{A} / \mathrm{A}$ & 79 & 0.422 & 81 & 0.433 & $1.045(0.693-1.574)$ & 0.834 & $1.079(0.696-1.674)$ & 0.734 \\
\hline $\mathrm{A} / \mathrm{G}$ & 75 & 0.401 & 83 & 0.444 & $1.192(0.790-1.797)$ & 0.402 & $1.262(0.812-1.961)$ & 0.302 \\
\hline G/G & 33 & 0.176 & 23 & 0.123 & $0.654(0.368-1.164)$ & 0.149 & $0.550(0.295-1.024)$ & 0.059 \\
\hline \multicolumn{9}{|c|}{$\chi 2=1.848 ; p=0.397$} \\
\hline A & 233 & 0.623 & 245 & 0.655 & $1.149(0.853-1.549)$ & 0.361 & $1.225(0.890-1.688)$ & 0.214 \\
\hline $\mathrm{G}$ & 141 & 0.377 & 129 & 0.345 & $0.870(0.675-1.173)$ & 0.361 & $0.816(0.593-1.124)$ & 0.214 \\
\hline \multicolumn{9}{|c|}{ g. $186640617 \mathrm{C}>\mathrm{T}$ of $P T G S 2 \quad(\mathrm{rs} 4648308)$} \\
\hline $\mathrm{C} / \mathrm{C}$ & 130 & 0.703 & 124 & 0.697 & $0.972(0.620-1.522)$ & 0.900 & $0.927(0.575-1.496)$ & 0.756 \\
\hline
\end{tabular}




\begin{tabular}{|c|c|c|c|c|c|c|c|c|}
\hline $\mathrm{C} / \mathrm{T}$ & 40 & 0.216 & 52 & 0.292 & $1.496(0.929-2.409)$ & 0.097 & $\begin{array}{l}b 1.673(0.994-2.815) \\
1.650 \\
(0.991-2.745)^{0.438}\end{array}$ & $\begin{array}{l}0.052 \\
0.054\end{array}$ \\
\hline $\mathbf{T} / \mathbf{T}$ & 14 & 0.076 & 2 & 0.011 & $\begin{array}{l}b_{0.129}(0.027-0.631) \\
0.139 \\
(0.031-0.620)^{0.932} \\
\end{array}$ & $\begin{array}{l}0.011 \\
0.010\end{array}$ & $\begin{array}{l}b_{0.103}(0.029-0.511) \\
0.110 \\
(0.023-0.522)^{0.946}\end{array}$ & $\begin{array}{l}0.003 \\
0.005\end{array}$ \\
\hline \multicolumn{9}{|c|}{$\chi 2=10.61 ; p=0.005$} \\
\hline $\mathrm{C}$ & 300 & 0.815 & 300 & 0.843 & $1.2148(0.824-1.790)$ & 0.327 & $1.208(0.799-1.828)$ & 0.370 \\
\hline $\mathrm{T}$ & 68 & 0.184 & 56 & 0.157 & $0.824(0.559-1.214)$ & 0.327 & $0.828(0.547-1.252)$ & 0.370 \\
\hline
\end{tabular}

1 


\section{Table 4 (on next page)}

Distribution of genotypes and alleles of rs2070729 (IRF1), rs5275 (PTGS2), rs4648308 (PTGS2), rs2166975 (TGFA), rs5029748 (IKBKB) and the risk of depression occurrence in male and female population

* 'adjusted OR' means OR adjusted for sex and age; for significant comparisons the superscript b means the bootstrap-boosted OR (resampling with replacement, 10000 iterations); all OR values without bootstrap analysis were calculated using cross-validation algorithm. Statistical power $(1-\beta)$ (calculated at $\alpha=0.05$ ) for significant comparisons given in superscripts. $p<0.05$ along with corresponding ORs are in bold 
Male

\begin{tabular}{|c|c|c|c|c|c|c|c|c|}
\hline \multirow{2}{*}{$\begin{array}{l}\text { Genotype } \\
\text { /Allele }\end{array}$} & \multicolumn{2}{|l|}{ Control } & \multicolumn{2}{|c|}{ Depression } & \multirow{2}{*}{ Crude OR (95\% CI) } & \multirow{2}{*}{$p$} & \multirow{2}{*}{$\begin{array}{l}\text { Adjusted OR (95\% } \\
\text { CI)* }\end{array}$} & \multirow{2}{*}{$p$} \\
\hline & Number & Frequency & Number & Frequency & & & & \\
\hline \multicolumn{9}{|c|}{ g.70677994G $>$ A of $T G F A(\mathrm{rs} 2166975)$} \\
\hline $\mathrm{A} / \mathrm{A}$ & 13 & 0.126 & 8 & 0.085 & $0.644(0.254-1.641)$ & 0.353 & $0.808(0.302-2.164)$ & 0.671 \\
\hline $\mathbf{A} / \mathbf{G}$ & 34 & 0.330 & 45 & 0.479 & $\begin{array}{l}b 1.843(1.037-3.272) \\
1.864 \\
(1.047-3.317)^{0.468}\end{array}$ & $\begin{array}{l}0.037 \\
0.034\end{array}$ & $\begin{array}{l}b_{2.318}(1.222-4.400) \\
2.280 \\
(1.218-4.268)^{0.733}\end{array}$ & $\begin{array}{l}0.010 \\
0.009\end{array}$ \\
\hline $\mathrm{G} / \mathrm{G}$ & 56 & 0.544 & 41 & 0.436 & $0.649(0.370-1.145)$ & 0.132 & $\begin{array}{l}b 0.476(0.250-0.905) \\
0.480 \\
(0.257-0.898)^{0.740}\end{array}$ & $\begin{array}{l}0.024 \\
0.022\end{array}$ \\
\hline \multicolumn{9}{|c|}{$\chi 2=4.640 ; p=0.098$} \\
\hline A & 60 & 0.291 & 61 & 0.709 & $\begin{array}{l}b_{0.109}(0.062-0.189) \\
0.113 \\
(0.065-0.195)^{0.992}\end{array}$ & $\begin{array}{l}<0.001 \\
<0.001\end{array}$ & $\begin{array}{l}b 0.106(0.060-0.186) \\
0.109 \\
(0.063-0.190)^{0.999}\end{array}$ & $\begin{array}{l}<0.001 \\
<0.001\end{array}$ \\
\hline G & 146 & 0.324 & 127 & 0.676 & $\begin{array}{l}b 9.005(5.242-15.468) \\
8.861 \\
(5.125-15.319)^{0.992}\end{array}$ & $\begin{array}{l}<0.001 \\
<0.001\end{array}$ & $\begin{array}{l}b 9.281(5.308-16.225) \\
9.135 \\
(5.260-15.867)^{0.999}\end{array}$ & $\begin{array}{l}<0.001 \\
<0.001\end{array}$ \\
\hline \multicolumn{9}{|c|}{ g.42140549G $>$ T of $I K B K B($ rs5029748) } \\
\hline $\mathrm{G} / \mathrm{G}$ & 61 & 0.610 & 53 & 0.589 & $0.916(0.510-1.644)$ & 0.769 & $0.955(0.514-1.776)$ & 0.885 \\
\hline G/T & 19 & 0.190 & 30 & 0.333 & $\begin{array}{l}b_{2.153}(1.082-4.288) \\
2.132 \\
(1.097-4.143)^{0.466}\end{array}$ & $\begin{array}{l}0.029 \\
0.026\end{array}$ & $\begin{array}{l}b 2.073(1.016-4.300) \\
2.063 \\
(1.024-4.154)^{0.423}\end{array}$ & $\begin{array}{l}0.049 \\
0.049\end{array}$ \\
\hline $\mathbf{T} / \mathbf{T}$ & 20 & 0.200 & 7 & 0.078 & $\begin{array}{l}{ }^{b} 0.316(0.118-0.849) \\
0.337 \\
(0.135-0.841)^{0.758}\end{array}$ & $\begin{array}{l}0.022 \\
0.020\end{array}$ & $\begin{array}{l}{ }^{b} 0.295(0.100-0.869) \\
{ }^{c} 0_{0.310} \\
(0.116-0.830)^{0.799}\end{array}$ & $\begin{array}{l}0.027 \\
0.021\end{array}$ \\
\hline$\chi 2=8.788$ & $=0.012$ & & & & & & & \\
\hline
\end{tabular}




\begin{tabular}{|c|c|c|c|c|c|c|c|c|}
\hline G & 141 & 0.705 & 136 & 0.756 & $1.211(0.817-1.796)$ & 0.341 & $1.305(0.826-2.061)$ & 0.253 \\
\hline $\mathrm{T}$ & 59 & 0.295 & 44 & 0.244 & $0.826(0.557-1.225)$ & 0.341 & $0.766(0.485-1.210)$ & 0.253 \\
\hline \multicolumn{9}{|c|}{ g. $186643058 \mathrm{~A}>\mathrm{G}$ of $P T G S 2$ (rs5275) } \\
\hline $\mathbf{A} / \mathbf{A}$ & 40 & 0.392 & 48 & 0.505 & $1.583(0.896-2.796)$ & 0.111 & $\begin{array}{l}b_{2.073}(0.999-4.300) \\
1.803 \\
(0.982-3.309)^{0.464}\end{array}$ & $\begin{array}{l}\mathbf{0 . 0 5 0} \\
0.057\end{array}$ \\
\hline $\mathrm{A} / \mathrm{G}$ & 41 & 0.402 & 37 & 0.389 & $0.949(0.534-1.687)$ & 0.858 & $0.852(0.462-1.575)$ & 0.611 \\
\hline $\mathrm{G} / \mathrm{G}$ & 21 & 0.206 & 10 & 0.105 & $0.454(0.201-1.028)$ & 0.057 & $\begin{array}{l}{ }^{b} 0.427(0.171-1.019) \\
0.438 \\
(0.186-1.032)^{0.599}\end{array}$ & $\begin{array}{l}0.052 \\
0.059\end{array}$ \\
\hline \multicolumn{9}{|c|}{$\chi^{2}=4.593 ; p=0.101$} \\
\hline $\mathbf{A}$ & 121 & 0.593 & 133 & 0.700 & $\begin{array}{l}b 1.588(1.031-2.445) \\
1.601 \\
(1.054-2.430)^{0.672}\end{array}$ & $\begin{array}{l}\mathbf{0 . 0 3 6} \\
\mathbf{0 . 0 2 7}\end{array}$ & $\begin{array}{l}b 1.659(1.064-2.586) \\
1.664 \\
(1.087-2.548)^{0.745}\end{array}$ & $\begin{array}{l}0.025 \\
0.019\end{array}$ \\
\hline $\mathbf{G}$ & 83 & 0.407 & 57 & 0.300 & $\begin{array}{l}b_{0.621}(0.399-0.968) \\
0.625 \\
(0.412-0.949)^{0.608}\end{array}$ & $\begin{array}{l}\mathbf{0 . 0 3 5} \\
0.027\end{array}$ & $\begin{array}{l}{ }^{b} 0.603(0.393-0.926) \\
0.601 \\
(0.393-0.920)^{0.666}\end{array}$ & $\begin{array}{l}0.021 \\
0.019\end{array}$ \\
\hline \multicolumn{9}{|c|}{ g. $186640617 \mathrm{C}>\mathrm{T}$ of $P T G S 2$ (rs4648308) } \\
\hline $\mathrm{C} / \mathrm{C}$ & 65 & 0.663 & 67 & 0.736 & $1.417(0.754-2.664)$ & 0.276 & $1.335(0.687-2.595)$ & 0.394 \\
\hline $\mathrm{C} / \mathrm{T}$ & 25 & 0.255 & 24 & 0.264 & $1.046(0.543-2.014)$ & 0.892 & $1.128(0.564-2.255)$ & 0.734 \\
\hline $\mathrm{T} / \mathrm{T}$ & 8 & 0.082 & 0 & 0 & - & - & - & - \\
\hline \multicolumn{9}{|c|}{$\chi 2=7.802 ; p=0.020$} \\
\hline $\mathbf{C}$ & 155 & 0.791 & 158 & 0.868 & $\begin{array}{l}b 1.772(0.996-3.162) \\
1.741 \\
(1.004-3.019)^{0.848}\end{array}$ & $\begin{array}{l}0.052 \\
0.048\end{array}$ & $\begin{array}{l}b 1.744(0.983-3.094) \\
1.751 \\
(1.007-3.040)^{0.854}\end{array}$ & $\begin{array}{l}0.049 \\
0.047\end{array}$ \\
\hline
\end{tabular}




\begin{tabular}{|c|c|c|c|c|c|c|c|c|}
\hline $\mathbf{T}$ & 41 & 0.209 & 24 & 0.132 & $\begin{array}{l}{ }^{b} 0.567(0.322-0.996) \\
0.574 \\
(0.331-0.996)^{0.553}\end{array}$ & $\begin{array}{l}0.049 \\
0.048\end{array}$ & $\begin{array}{l}b_{0.566}(0.315-0.999) \\
0.571 \\
(0.329-0.993)^{0.558}\end{array}$ & $\begin{array}{l}0.049 \\
0.047\end{array}$ \\
\hline \multicolumn{9}{|c|}{ Female } \\
\hline \multirow{2}{*}{$\begin{array}{l}\text { Genotype } \\
\text { /Allele } \\
\end{array}$} & \multicolumn{2}{|c|}{ Control } & \multicolumn{2}{|c|}{ Depression } & \multirow{2}{*}{ Crude OR (95\% CI) } & \multirow{2}{*}{$p$} & \multirow{2}{*}{$\begin{array}{l}\text { Adjusted OR }(95 \% \\
\text { CI })^{*}\end{array}$} & \multirow{2}{*}{$p$} \\
\hline & Number & Frequency & Number & Frequency & & & & \\
\hline \multicolumn{9}{|c|}{ g.132484229C >A of IRF1 (rs2070729) } \\
\hline $\mathrm{A} / \mathrm{A}$ & 20 & 0.244 & 20 & 0.215 & $0.849(0.417-1.730)$ & 0.650 & $0.655(0.297-1.437)$ & 0.291 \\
\hline $\mathbf{A} / \mathbf{C}$ & 32 & 0.390 & 48 & 0.516 & $1.667(0.910-3.056)$ & 0.096 & $\begin{array}{l}b_{2} .016(1.025-3.966) \\
1.936 \\
(1.003-3.738)^{0.508}\end{array}$ & $\begin{array}{l}0.042 \\
0.049\end{array}$ \\
\hline $\mathrm{C} / \mathrm{C}$ & 30 & 0.366 & 25 & 0.269 & $0.637(0.334-1.216)$ & 0.169 & $0.657(0.328-1.318)$ & 0.237 \\
\hline \multicolumn{9}{|c|}{$\chi 2=2.975 ; p=0.226$} \\
\hline A & 72 & 0.439 & 88 & 0.473 & $1.136(0.756-1.706)$ & 0.539 & $1.159(0.730-1.840)$ & 0.532 \\
\hline $\mathrm{C}$ & 92 & 0.561 & 98 & 0.527 & $0.880(0.586-1.322)$ & 0.539 & $0.862(0.544-1.370)$ & 0.532 \\
\hline \multicolumn{9}{|c|}{ g. $186643058 \mathrm{~A}>\mathrm{G}$ of $P T G S 2$ (rs5275) } \\
\hline $\mathrm{A} / \mathrm{A}$ & 39 & 0.459 & 33 & 0.359 & $0.661(0.359-1.211)$ & 0.176 & $0.595(0.309-1.143)$ & 0.119 \\
\hline $\mathbf{A} / \mathbf{G}$ & 34 & 0.400 & 46 & 0.500 & $1.500(0.823-2.734)$ & 0.183 & $\begin{array}{l}1.962(1.024-3.758) \\
1.952 \\
(1.017-3.746)^{0.524}\end{array}$ & $\begin{array}{l}0.042 \\
0.044 \\
\end{array}$ \\
\hline $\mathrm{G} / \mathrm{G}$ & 12 & 0.141 & 13 & 0.141 & $1.001(0.427-2.344)$ & 0.998 & $0.718(0.284-1.812)$ & 0.483 \\
\hline \multicolumn{9}{|c|}{$\chi 2=2.006 ; p=0.356$} \\
\hline A & 112 & 0.659 & 112 & 0.609 & $0.810(0.527-1.244)$ & 0.336 & $0.833(0.524-1.325)$ & 0.441 \\
\hline G & 58 & 0.341 & 72 & 0.391 & $1.235(0.804-1.898)$ & 0.336 & $0.816(0.755-1.908)$ & 0.441 \\
\hline
\end{tabular}




\begin{tabular}{|c|c|c|c|c|c|c|c|c|}
\hline $\mathrm{C} / \mathrm{C}$ & 65 & 0.756 & 57 & 0.655 & $0.614(0.315-1.195)$ & 0.148 & $0.595(0.294-1.205)$ & 0.149 \\
\hline $\mathbf{C} / \mathbf{T}$ & 15 & 0.174 & 28 & 0.322 & $\begin{array}{l}b_{2.270}(1.100-4.684) \\
2.246 \\
(1.098-4.596)^{0.806}\end{array}$ & $\begin{array}{l}\mathbf{0 . 0 2 7} \\
\mathbf{0 . 0 2 7}\end{array}$ & $\begin{array}{l}b_{2} .574(1.224-5.415) \\
2.533 \\
(1.178-5.449)^{0.587}\end{array}$ & $\begin{array}{l}0.013 \\
0.017\end{array}$ \\
\hline $\mathrm{T} / \mathrm{T}$ & 6 & 0.070 & 2 & 0.023 & $0.314(0.061-1.620)$ & 0.163 & $0.211(0.037-1.211)$ & 0.081 \\
\hline \multicolumn{9}{|c|}{$\chi 2=6.449 ; p=0.039$} \\
\hline $\mathrm{C}$ & 145 & 0.843 & 142 & 0.816 & $0.843(0.495-1.435)$ & 0.530 & $0.853(0.469-1.553)$ & 0.603 \\
\hline $\mathrm{T}$ & 27 & 0.157 & 32 & 0.184 & $1.186(0.697-2.018)$ & 0.530 & $1.172(0.644-2.135)$ & 0.603 \\
\hline
\end{tabular}

1 


\section{Table 5 (on next page)}

Gene-gene interactions of rs1800469 (TGFB1), rs2070729 (IRF1), rs5275 (PTGS2), rs4648308 (PTGS2), rs2166975 (TGFA), rs5029748 (IKBKB) and the risk of depression occurrence

* 'adjusted OR' means OR adjusted for sex and age; for significant comparisons the superscript b means the bootstrap-boosted OR (resampling with replacement, 10000 iterations); all OR values without bootstrap analysis were calculated using cross-validation algorithm. Statistical power $(1-\beta)$ (calculated at $\alpha=0.05)$ for significant comparisons given in superscripts. $p<0.05$ along with corresponding ORs are in bold 


\begin{tabular}{|c|c|c|c|c|c|c|c|c|}
\hline \multirow{2}{*}{$\begin{array}{l}\text { Combined } \\
\text { genotype }\end{array}$} & \multicolumn{2}{|c|}{ Control $(n=180)$} & \multicolumn{2}{|c|}{ Depression } & \multirow{2}{*}{ Crude OR (95\% CI) } & \multirow{2}{*}{$p$} & \multirow[b]{2}{*}{ Adjusted OR (95\% CI) } & \multirow[b]{2}{*}{$\boldsymbol{p}$} \\
\hline & Number & Frequency & Number & Frequency & & & & \\
\hline \multicolumn{9}{|c|}{ g.41354391A $>\mathrm{G}$ of $T G F B 1(\mathrm{rs} 1800469)-\mathrm{g} .70677994 \mathrm{G}>\mathrm{A}$ of $T G F A(\mathrm{rs} 2166975)$} \\
\hline $\mathbf{A} / \mathbf{G}-\mathbf{A} / \mathbf{G}$ & 24 & 0.126 & 35 & 0.186 & $1.592(0.904-2.803)$ & 0.106 & $\begin{array}{l}b 1.906(1.032-3.518) \\
1.898 \\
(1.036-3.477)^{0.490}\end{array}$ & $\begin{array}{l}0.039 \\
0.038\end{array}$ \\
\hline \multicolumn{9}{|c|}{ g.70677994G $>$ A of $T G F A(\mathrm{rs} 2166975)-$ g.132484229C $>$ A of $I R F 1(\mathrm{rs} 2070729)$} \\
\hline $\mathbf{A} / \mathbf{G}-\mathbf{A} / \mathbf{C}$ & 27 & 0.141 & 45 & 0.241 & $\begin{array}{l}{ }^{b} 1.951(1.152-3.305) \\
1.925 \\
(1.136-3.262)^{0.554}\end{array}$ & $\begin{array}{l}0.013 \\
0.015\end{array}$ & $\begin{array}{l}b_{2.117}(1.224-3.660) \\
2.092 \\
(1.193-3.660)^{0.667}\end{array}$ & $\begin{array}{l}0.007 \\
0.010\end{array}$ \\
\hline \multicolumn{9}{|c|}{ g.70677994G>A of $T G F A(\mathrm{rs} 2166975)-\mathrm{g} .186643058 \mathrm{~A}>\mathrm{G}$ of $P T G S 2$ (rs5275) } \\
\hline G/G-G/G & 22 & 0.115 & 8 & 0.043 & $\begin{array}{l}b_{0.320}(0.127-0.807) \\
0.341 \\
(0.148-0.788)^{0.828}\end{array}$ & $\begin{array}{l}0.016 \\
0.012\end{array}$ & $\begin{array}{l}b_{0.223} 0.0870 .574 \\
0.233 \\
(0.094-0.579)^{0.940}\end{array}$ & $\begin{array}{l}0.002 \\
0.002\end{array}$ \\
\hline $\mathbf{A} / \mathbf{A}-\mathbf{G} / \mathbf{G}$ & 7 & $\mathbf{0 . 0 3 7}$ & 1 & 0.005 & $0.139(0.017-1.141)$ & 0.066 & $\begin{array}{l}b 0.167(0.027-1.031) \\
0.129 \\
(0.014-1.159)^{0.805}\end{array}$ & $\begin{array}{l}0.054 \\
0.068\end{array}$ \\
\hline A/G-G/G & 4 & 0.021 & 14 & 0.074 & $\begin{array}{l}b 3.581(1.233-13.12) \\
3.761 \\
(1.215-11.647)^{0.291}\end{array}$ & $\begin{array}{l}0.026 \\
0.022\end{array}$ & $\begin{array}{l}b 4.264(1.416-12.839) \\
4.137 \\
(1.263-13.545)^{0.291}\end{array}$ & $\begin{array}{l}0.010 \\
0.019\end{array}$ \\
\hline
\end{tabular}

g.70677994G $>$ A of TGFA (rs2166975)- g.186640617C $>$ T of PTGS2 (rs4648308) 


\begin{tabular}{|c|c|c|c|c|c|c|c|c|}
\hline G/G-T/T & 12 & 0.063 & 1 & 0.005 & $\begin{array}{l}{ }^{b} 0.087(0.013-0.638) \\
0.080 \\
(0.010-0.620)^{0.942}\end{array}$ & $\begin{array}{l}0.018 \\
0.016\end{array}$ & $\begin{array}{l}\boldsymbol{b}_{0.057}(0.011-0.312) \\
0.051 \\
(0.006-0.420)^{0.948}\end{array}$ & $\begin{array}{l}0.001 \\
0.006\end{array}$ \\
\hline $\mathbf{A} / \mathbf{G}-\mathbf{C} / \mathbf{T}$ & 10 & 0.052 & 25 & 0.133 & $\begin{array}{l}b 3.005(1.242-7.269) \\
2.776 \\
(1.294-5.956)^{0.584}\end{array}$ & $\begin{array}{l}0.015 \\
0.009\end{array}$ & $\begin{array}{l}b 3.240(1.442-7.280) \\
3.115 \\
(1.397-6.944))^{0.663}\end{array}$ & $\begin{array}{l}0.004 \\
0.005\end{array}$ \\
\hline \multicolumn{9}{|c|}{ g.70677994G $>$ A of $T G F A(\mathrm{rs} 2166975)-$ g.42140549G $>$ T of $I K B K B($ rs5029748) } \\
\hline G/G-T/T & 23 & 0.120 & 9 & 0.048 & $\begin{array}{l}{ }^{b} 0.362(0.156-0.840) \\
0.367 \\
(0.165-0.816)^{0.801}\end{array}$ & $\begin{array}{l}0.018 \\
0.014\end{array}$ & $\begin{array}{l}b_{0.286}(0.106-0.772) \\
0.306 \\
\left(0.1310 .719^{0.882}\right.\end{array}$ & 0.007 \\
\hline A/G-G/T & 11 & 0.058 & 24 & 0.128 & $\begin{array}{l}{ }^{b} 2.393(1.136-5.042) \\
2.395 \\
(1.138-5.041)^{0.472}\end{array}$ & $\begin{array}{l}0.022 \\
0.021\end{array}$ & $\begin{array}{l}{ }^{b} 2.645(1.184-5.910) \\
2.621 \\
(1.208-5.688)^{0.571}\end{array}$ & $\begin{array}{l}0.018 \\
0.015\end{array}$ \\
\hline \multicolumn{9}{|c|}{ g.132484229C $>$ A of $I R F 1$ (rs2070729)- g.186643058A>G of PTGS2 (rs5275) } \\
\hline $\mathbf{A} / \mathbf{C}-\mathbf{A} / \mathbf{G}$ & 29 & 0.152 & 49 & 0.261 & $\begin{array}{l}b_{2.077}(1.206-3.576) \\
1.969 \\
(1.180-3.286)^{0.614}\end{array}$ & $\begin{array}{l}0.008 \\
0.009\end{array}$ & $\begin{array}{l}{ }^{b} 1.863(1.022-3.394) \\
1.844 \\
(1.069-3.180)^{0.515}\end{array}$ & $\begin{array}{l}0.042 \\
0.028\end{array}$ \\
\hline \multicolumn{9}{|c|}{ g.132484229C $>$ A of $I R F 1$ (rs2070729)- g.42140549G>T of $I K B K B($ rs5029748) } \\
\hline $\mathrm{A} / \mathrm{C}-\mathbf{G} / \mathbf{T}$ & 16 & 0.084 & 29 & 0.154 & $\begin{array}{l}b_{2.032}(1.036-3.989) \\
1.995 \\
(1.044-3.810)^{0.402}\end{array}$ & $\begin{array}{l}0.039 \\
0.036\end{array}$ & $\begin{array}{l}{ }^{b} 1.918(0.935-3.931) \\
1.901 \\
(0.958-3.774)^{0.362}\end{array}$ & $\begin{array}{l}0.075 \\
0.066\end{array}$ \\
\hline
\end{tabular}

g.42140549G $>\mathrm{T}$ of $I K B K B$ (rs5029748)- g.186643058A $>\mathrm{G}$ of $P T G S 2$ (rs5275) 


\begin{tabular}{|c|c|c|c|c|c|c|c|c|}
\hline T/T-G/G & 14 & 0.073 & 2 & 0.011 & $\begin{array}{l}{ }^{b} 0.131(0.037-0.598) \\
0.136 \\
(0.030-0.607)^{0.936}\end{array}$ & $\begin{array}{l}0.008 \\
0.009\end{array}$ & $\begin{array}{l}b_{0.126}(0.027-0.589) \\
0.132 \\
(0.028-0.610)^{0.939}\end{array}$ & $\begin{array}{l}0.008 \\
0.009\end{array}$ \\
\hline $\mathbf{G} / \mathbf{T}-\mathbf{A} / \mathbf{G}$ & 16 & 0.084 & 31 & 0.165 & $\begin{array}{l}b_{2.235}(1.114-4.487) \\
2.160 \\
(1.138-4.098)^{0.512}\end{array}$ & $\begin{array}{l}0.024 \\
0.018\end{array}$ & $\begin{array}{l}{ }^{b} 1.933(0.883-4.233) \\
1.894 \\
(0.968-3.704)^{0.357}\end{array}$ & $\begin{array}{l}0.008 \\
0.009\end{array}$ \\
\hline \multicolumn{9}{|c|}{ g.42140549G $>\mathrm{T}$ of $I K B K B(\mathrm{rs} 5029748)-\mathrm{g} .186640617 \mathrm{C}>\mathrm{T}$ of $P T G S 2(\mathrm{rs} 4648308)$} \\
\hline G/T-C/T & 4 & 0.021 & 19 & 0.101 & $\begin{array}{l}b_{5.013}(1.531-18.121) \\
5.256 \\
(1.753-15.760)^{0.291}\end{array}$ & $\begin{array}{l}0.005 \\
0.003\end{array}$ & $\begin{array}{l}b 4.164(1.232-15.343) \\
4.320 \\
(1.390-13.428)^{0.286}\end{array}$ & $\begin{array}{l}0.035 \\
0.011\end{array}$ \\
\hline
\end{tabular}

